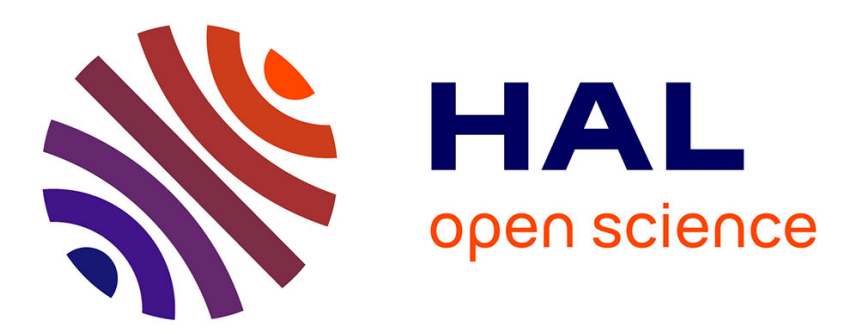

\title{
Electroanalysis of microbial anodes for bioelectrochemical systems: basics, progress and perspectives
}

\author{
Mickaël Rimboud, Diana Pocaznoi, Benjamin Erable, Alain Bergel
}

\section{To cite this version:}

Mickaël Rimboud, Diana Pocaznoi, Benjamin Erable, Alain Bergel. Electroanalysis of microbial anodes for bioelectrochemical systems: basics, progress and perspectives. Physical Chemistry Chemical Physics, 2014, vol. 16 ( $\mathrm{n}^{\circ} 31$ ), pp. 16349-16366. 10.1039/c4cp01698j . hal-01250378

\section{HAL Id: hal-01250378 https://hal.science/hal-01250378}

Submitted on 4 Jan 2016

HAL is a multi-disciplinary open access archive for the deposit and dissemination of scientific research documents, whether they are published or not. The documents may come from teaching and research institutions in France or abroad, or from public or private research centers.
L'archive ouverte pluridisciplinaire HAL, est destinée au dépôt et à la diffusion de documents scientifiques de niveau recherche, publiés ou non, émanant des établissements d'enseignement et de recherche français ou étrangers, des laboratoires publics ou privés. 


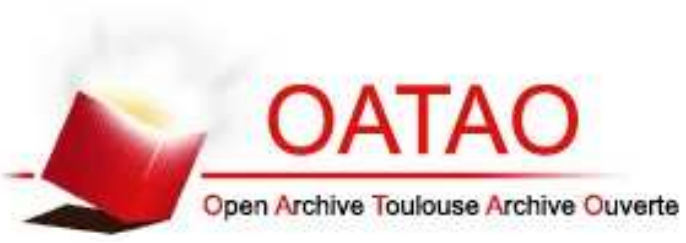

\section{Open Archive TOULOUSE Archive Ouverte (OATAO)}

OATAO is an open access repository that collects the work of Toulouse researchers and makes it freely available over the web where possible.

This is an author-deposited version published in : http://oatao.univ-toulouse.fr/ Eprints ID : 12069

To link to this article : DOI:10.1039/c4cp01698j

URL : http://dx.doi.org/10.1039/c4cp01698j

\section{To cite this version :}

Rimboud, Mickaël and Pocaznoi, Diana and Erable, Benjamin and Bergel, Alain Electroanalysis of microbial anodes for bioelectrochemical systems: basics, progress and perspectives. (2014) Physical Chemistry Chemical Physics, vol. 16 (n 31). pp. 16349-16366. ISSN 1463-9076

Any correspondance concerning this service should be sent to the repository administrator: staff-oatao@listes-diff.inp-toulouse.fr 


\title{
Electroanalysis of microbial anodes for bioelectrochemical systems: basics, progress and perspectives
}

\author{
M. Rimboud, D. Pocaznoi, B. Erable and A. Bergel* \\ Over about the last ten years, microbial anodes have been the subject of a huge number of fundamental \\ studies dealing with an increasing variety of possible application domains. Out of several thousands of \\ studies, only a minority have used 3-electrode set-ups to ensure well-controlled electroanalysis conditions. \\ The present article reviews these electroanalytical studies with the admitted objective of promoting this \\ type of investigation. A first recall of basics emphasises the advantages of the 3-electrode set-up compared \\ to microbial fuel cell devices if analytical objectives are pursued. Experimental precautions specifically \\ relating to microbial anodes are then noted and the existing experimental set-ups and procedures are \\ reviewed. The state-of-the-art is described through three aspects: the effect of the polarisation potential \\ on the characteristics of microbial anodes, the electroanalytical techniques, and the electrode. We hope \\ that the final outlook will encourage researchers working with microbial anodes to strengthen their \\ engagement along the multiple exciting paths of electroanalysis.
}

\section{Introduction}

It was less than fifteen years ago that the capability of a bacterium (Shewanella putrefaciens) to exchange electrons with an electrode without the involvement of an artificial redox mediator was discovered. ${ }^{1,2}$ Similar extracellular electron exchange with electrodes was then demonstrated with multispecies biofilms formed from marine sediments. ${ }^{3,4}$ A wide variety of microbial electrochemical technologies (METs) have since emerged through the integration of electrochemically active (EA) microorganisms into conventional electrochemical processes. The microbial fuel cell (MFC) was the pioneer system in 2002, followed in 2005 by the microbial electrolysis cell (MEC) for hydrogen production. Other innovative devices were then proposed in various application domains such as bioremediation, water desalination, metal recovery, synthesis, etc., as reviewed in several recent articles. ${ }^{5-7}$ The initial very enthusiastic economic forecasts have sometimes been toned down, ${ }^{8,9}$ while others continue to predict a great future with large-size applications. Whatever its economic development may be, microbial electroactivity is undoubtedly an exceedingly exciting new concept, which deserves much fundamental work so that it can be fully understood and the possible economically efficient applications clearly identified.

Microbial anodes are the pillars of most of these processes (except for synthesis cells, which have mainly used microbial

Laboratoire de Génie Chimique, CNRS - Université de Toulouse, 4 allée Emile Monso, 31432 Toulouse, France. E-mail: alain.bergel@ensiacet.fr biocathodes so $\left.\operatorname{far}^{8}\right)$. A microbial anode is made by a microbial species (pure culture) or a microbial community that adheres to the electrode surface and forms a biofilm. The biofilm oxidises organic compounds (sugars, alcohols, acetate, volatile fatty acids, complex organic matter, etc.) and transfers the resulting electrons to the electrode through various electron transfer (ET) pathways, while direct oxidation of the substrate on the clean electrode surface would be so slow that it can be said not to occur.

The large majority of studies dealing with microbial anodes have been carried out in complete electrochemical reactors, mainly MFCs. Such set-ups are obviously fully appropriate to assess the impact of electrode materials, cell architecture, operating conditions and other parameters on the overall process efficiency, they are indispensable in some cases such as testing MFCs in natural environments, but they do not characterise the intrinsic behaviour of the bioanodes. The different biological and physicochemical steps that interact in an MFC affect the overall reaction rate and can drastically impact the bioanode formation and performance. For instance, the cathode, which is a strong rate-limiting element in most MFCs, may, by restricting the electron flow, hinder the development of the bioanode. The internal resistance of the reactor is another widespread ratelimiting feature. Moreover, the potential applied to the anode in an MFC can vary greatly. Accurate information on the bioanode is consequently hard to extract from current measurements as they result from the interaction of numerous steps, which can be rate-limiting and can evolve with time. 
The careful design of a 3-electrode set-up should be a prerequisite for characterising microbial anodes, firstly because it ensures that the bioanode is the sole rate-limiting step that controls the current measured and, secondly, because the potential applied to the bioanode is thus perfectly controlled. From a fundamental point of view, the value of the applied potential during EA biofilm formation is obviously an important parameter that must be carefully controlled. ${ }^{10}$ From a practical point of view, ridding the bioanodes of the different rate-limiting steps that occur in an MFC has led to impressive success, demonstrating that bioanodes can produce current densities as high as several hundreds of $\mathrm{A} \mathrm{m}^{-2} \cdot{ }^{11}$ Surprisingly, among the thousands of studies devoted to METs, only a minority have used 3-electrode analytical set-ups to investigate microbial anodes. One reason may be found in the emerging situation of METs, which has pushed priorities towards demonstrating the process feasibility with complete reactors rather than characterising bioanodes in electroanalytical cells. The situation is now changing: with the increased maturity of the domain an increasing number of studies implement electroanalytical conditions. Moreover, the possibility of manufacturing relatively cheap potentiostats may reinforce this trend. ${ }^{12}$

The purpose of the present article is to make a first review of the studies devoted to the formation and characterisation of microbial anodes under well-controlled electroanalytical conditions. The article recalls the basics of 3-electrode cells and then comments on the different issues that have been investigated using these cells: effect of the applied potential on bioanode properties with pure culture or with multispecies inocula, implementation of transient electrochemical analytical techniques, and first attempts at spectroelectrochemistry. We hope that this review illustrates the broad range of approaches that electroanalysis has started to open up for investigating microbial anodes. Care is taken to describe how the 3-electrode set-ups can be adapted to the particular constraints of microbial systems, trying to anticipate possible bias, with the admitted objective of strengthening the engagement of the research groups in electroanalysis of microbial anodes.

\section{Back to basics}

\subsection{Difference between MFCs and 3-electrode set-ups from the analyst's point of view}

MFCs bring numerous and varied processes into play, which interact and, together, control the overall performance. Thus, both the current $(I)$ and the potential of the anode $\left(E_{\mathrm{A}}\right)$ can vary, particularly during the initial phase of EA biofilm formation. This is illustrated in Fig. 1, based on a simple theoretical scheme. Initially, the clean anode is unable to oxidise the substrate or gives only very low currents at very high potentials. The electrocatalytic capability of the anode then improves with the formation of the EA biofilm, reaching maturity after several hours or, more often, a few days. The current-potential curve of the mature bioanode is plotted in Fig. 1 according to NernstMonod kinetics: ${ }^{13}$

$$
I_{\mathrm{A}}=I_{\mathrm{A}, \max } /\left(1+\exp \left[-n F / R T\left(E_{\mathrm{A}}-E_{\mathrm{A}, 1 / 2}\right)\right]\right)
$$

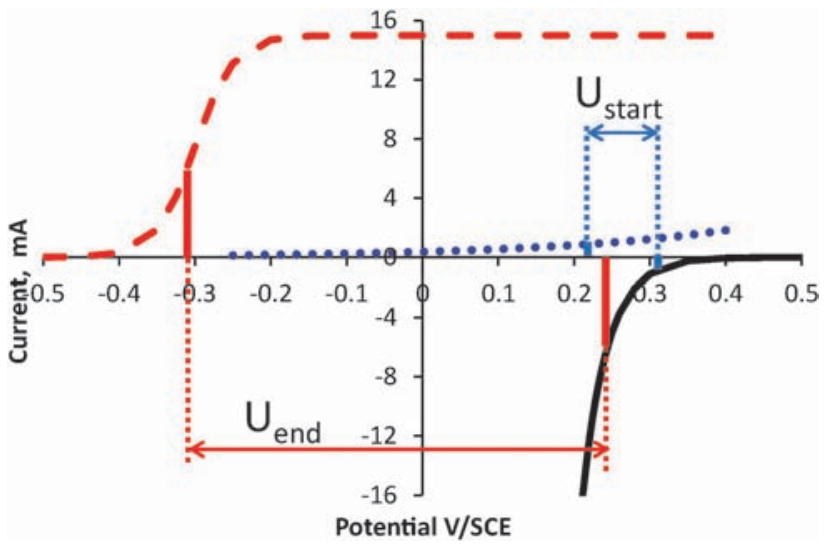

Fig. 1 Theoretical scheme of current-potential curves of a bioanode (positive current) and an oxygen-reducing abiotic cathode (negative current) in an MFC. Initially, the anode had very slow kinetics of substrate oxidation (dotted blue line). It then improved with the formation of the EA biofilm to reach Nernst-Monod kinetics (dashed red line, eqn (1)). The cathode current-potential curve (continuous black line) was chosen to be representative of the abiotic reduction of oxygen. The anode and cathode were connected through an electrical resistance of $100 \Omega$. The graphical location of the MFC operating points according to eqn (2) gave an initial current of $0.9 \mathrm{~mA}$, i.e. cell voltage of $90 \mathrm{mV}\left(E_{\mathrm{A}}=0.22, E_{\mathrm{C}}=0.31 \mathrm{~V} / \mathrm{SCE}\right)$. When the EA biofilm was developed, the current was $5.6 \mathrm{~mA}$ and the cell voltage $560 \mathrm{mV}\left(E_{\mathrm{A}}=-0.31, E_{\mathrm{C}}=0.25 \mathrm{~V} / \mathrm{SCE}\right)$

where $I_{\mathrm{A}}$ is the current provided by the bioanode (A), $I_{\mathrm{A}, \max }$ is the maximum current that the anode can provide $(15 \mathrm{~mA}), n$ is the number of electrons exchanged $(n=1), F$ is the Faraday constant (96485 $\mathrm{C}$ per mole $\mathrm{e}^{-}$), $R$ is the gas constant $\left(8.314 \mathrm{~J} \mathrm{~mol}^{-1} \mathrm{~K}^{-1}\right.$ ), $T$ is the temperature $(298 \mathrm{~K}), E_{\mathrm{A}}$ is the anode potential (V/SCE) and $E_{\mathrm{A}, 1 / 2}$ is the potential at which the current provided by the bioanode is half of $I_{\mathrm{A}, \max }(-0.3 \mathrm{~V} / \mathrm{SCE})$. The cathode currentpotential was chosen to be representative of the abiotic reduction of oxygen.

The operating point of the MFC is determined by locating the anode and cathode potentials on the cathode and anode current-potential curves, respectively, taking care that Ohm's law was satisfied:

$$
E_{\mathrm{C}}-E_{\mathrm{A}}=R_{\mathrm{ext}} I=U
$$

where $E_{\mathrm{A}}$ and $E_{\mathrm{C}}$ are the anode and the cathode potentials, respectively, $R_{\text {ext }}$ is the external electrical resistance, and $U$ is the cell voltage. The anode and cathode currents must be kept equal and the pair of values $E_{\mathrm{A}}$ and $E_{\mathrm{C}}$ can be determined simply by graphical trials and errors to satisfy eqn (2). The ohmic drop is neglected in this simplified approach. At the beginning of the MFC run, the current is very low and, according to eqn (2), the anode and cathode potentials are close. For example, with an electrical resistance of $100 \Omega$, the current is $0.9 \mathrm{~mA}$ and the cell voltage $U_{\text {start }}$ is only $90 \mathrm{mV}$, which means that the bioanode starts to be formed at potential values close to the cathode potential $\left(E_{\mathrm{A}}=0.22 \mathrm{~V} / \mathrm{SCE}\right)$. When the electrocatalytic capability of the bioanode improves, its potential changes to more negative values. In the present example, the mature bioanode provides $5.6 \mathrm{~mA}$ and works at a potential 
around $-0.31 \mathrm{~V} / \mathrm{SCE}$. In consequence, the potential of the bioanode changes by more than $500 \mathrm{mV}$ during its formation phase (from +0.22 to $-0.31 \mathrm{~V} / \mathrm{SCE}$ ), simply through the evolution of its kinetics.

The scheme of Fig. 1 does not take all the other possible sources of variation into account: changes in cathode kinetics, changes in ionic conductivity of the solution, biofouling of the separator (if any) and/or of the cathode, etc., which can enhance or reduce the variation of the potential at which the bioanode works. The bioanode potential can vary greatly in an MFC in a way that is hard to predict.

In contrast, an electroanalysis cell is based on a 3-electrode set-up, in which the potential applied to the bioanode (working electrode) is rigorously controlled and is not affected by variations of the kinetics of the bioanode or any other variation of the system.

\subsection{How to design a 3-electrode set-up for microbial anodes}

The potential of the reference electrodes commonly used in bioanode studies depends on the $\mathrm{KCl}$ concentration of their internal solution: $\mathrm{KCl}$ saturated calomel electrode $(0.241 \mathrm{~V} / \mathrm{SHE}$ at $25{ }^{\circ} \mathrm{C}$ ), or $\mathrm{KCl}$ saturated or $\mathrm{KCl} 1 \mathrm{M}$ silver/silver chloride electrodes ( 0.197 or $0.235 \mathrm{~V} / \mathrm{SHE}$ at $25^{\circ} \mathrm{C}$ ). Designing microbial bioanodes requires experiments lasting several days or weeks. It is consequently of great importance to control, and, if necessary, correct the possible deviation of the potential of the reference with time due to the slow diffusion of $\mathrm{KCl}$ out of the electrode. For example, the potential of the calomel electrode varies from $0.241 \mathrm{~V} / \mathrm{SHE}$ when $\mathrm{KCl}$ is saturated to 0.280 or $0.334 \mathrm{~V} / \mathrm{SHE}$ when $\mathrm{KCl}$ concentration decreases to 1 or $0.1 \mathrm{M}$. It is consequently essential to check the potential of the reference periodically during long-lasting experiments to ensure the accuracy of the results.

Except in a few cases ${ }^{14}$ and obviously those developed in marine environments, most microbial bioanodes do not accept high salinity because the microbial cells do not tolerate high osmotic pressure through their cytoplasmic membrane. In consequence, the anolyte salinity has two opposite effects in a MET: at low values, increasing the salinity increases the current because of the diminution of the internal resistance of the reactor, and at high values it decreases the current by deteriorating the EA microbial cells. The anolytes used in most MET studies thus have low ionic conductivities, around 1 or $2 \mathrm{~S} \mathrm{~m}^{-1}$. For analytical purposes, a 3-electrode electroanalytical set-up overcomes this drawback and the solution conductivity has almost no effect on the measurements, provided that minimum precautions are taken. Only the ohmic drop due to the solution between the bioanode surface and the reference electrode can alter the value of the applied potential. The tip of the reference electrode must consequently be as close as possible to the bioanode. It is worth noting that a 3-electrode set-up, because it suppresses the effect of the internal resistance of the reactor on the current, allows direct assessment of the impact of salinity on the bioanode performance.

Actually, in a 3-electrode set-up, the potential of the working electrode is controlled accurately at the point of its surface that is closest to the tip of the reference. With a large electrode surface area, particularly in solutions of low ionic conductivity, the working electrode may work with different local Nernst potentials. A gradient of local potential on the bioanode surface may also occur if the conductivity of the electrode material is too low. These situations must be avoided by using a small working electrode surface area. Larger surface areas of the auxiliary electrode and of the separator, if any, are then required to ensure a uniform distribution of the current lines.

The surface area of the anode must be small in comparison with the volume of the solution in order to minimise the variation in the chemical composition of the solution due to electrochemical reactions. This condition is of particular importance for bioanodes, because they require long polarisation times to be formed. In batch mode, the growth phase of the EA biofilm may induce the consumption of a significant part of the substrate, in which case the substrate concentration becomes too low for full development of the bioanode to be reached.

Usually, several successive batch cycles are performed to form and characterise a bioanode. In each cycle, the current first increases up to a maximum value and then decreases to zero due to the depletion of the substrate. When the current falls to zero a new batch is performed by replacing the solution with fresh medium or just by adding a new dose of the substrate. After medium replacement or the addition of a new dose of the substrate, a microbial anode often needs several hours to "reactivate" and recover its maximum performance. With such slow kinetics, if the anode surface area is too large with respect to the volume of solution, a considerable amount of the substrate is consumed during the time required for the bioanode to reactivate. The bioanode thus reaches maximum electrocatalytic efficiency in a medium considerably depleted in the substrate. The large consumption of the substrate during the reactivation phase can lead the performance of the bioanode being underestimated. This phenomenon is illustrated through a simple theoretical model in Fig. 2. A mature bioanode is assumed with a speculated exponential reactivation law:

$$
j=j_{\max } \exp (-\tau t) \frac{C}{K_{\mathrm{M}}+C}
$$

where $j$ is the current density, $\tau$ is the time constant for bioanode reactivation, $t$ is the time, $C$ is the substrate concentration, and $K_{\mathrm{M}}$ is a Michaelis-type constant. In the current state of knowledge, the exponential part of this equation has no physical meaning because information on the reactivation mechanisms after the addition of a new dose of the substrate is lacking (see Section 5.1). A phenomenological equation is used here, which gives a reasonable pattern of current recovery according to common experimental data. ${ }^{15}$ In contrast, the second part of eqn (3), which assumes current variation according to a Michaelis-Menten-type equation, has already been used to model EA biofilms. ${ }^{16}$

Fig. 2 shows that varying only the anode surface area from 10 to $100 \mathrm{~cm}^{2}$ (all other parameters remaining unchanged) 

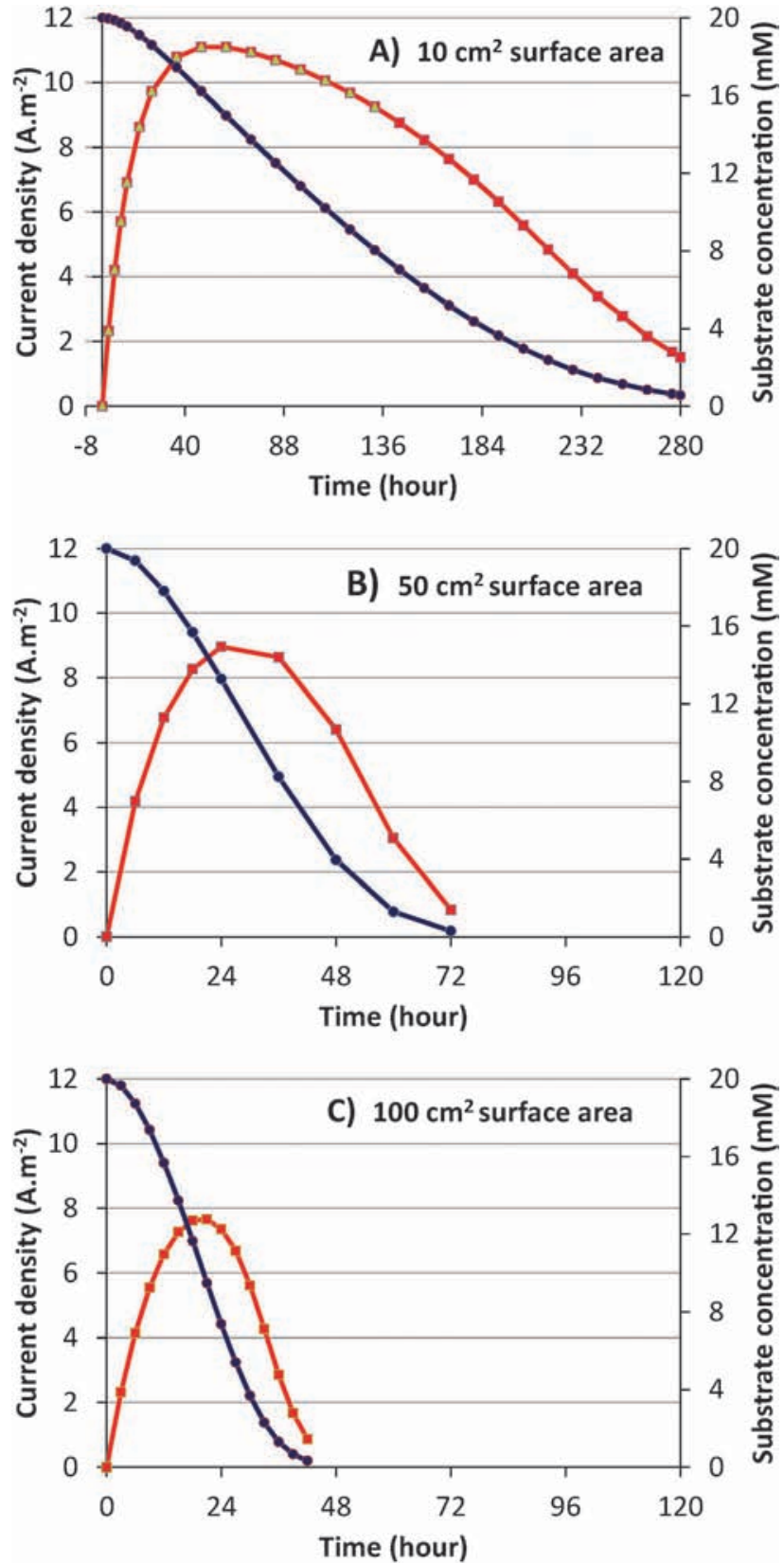

Fig. 2 Theoretical current density and substrate concentration as a function of time in electroanalysis cells with different bioanode surface areas. The current density (red squares) was calculated according to eqn (3) with the following parameter values: maximum current density $j_{\max }=15 \mathrm{~A} \mathrm{~m}^{-2}$, time constant for bioanode reactivation $\tau=2 \times 10^{-5} \mathrm{~s}^{-1}\left(1.728 \mathrm{~d}^{-1}\right)$, Michaelis-Menten-type constant $K_{\mathrm{M}}=5 \mathrm{mM}$. The initial concentration of the substrate was $20 \mathrm{mM}$ and the cell volume was $0.5 \mathrm{~L}$. The surface area of the bioanode was the only parameter changed: (A) $10 \mathrm{~cm}^{2}$, (B) $50 \mathrm{~cm}^{2}$ and (C) $100 \mathrm{~cm}^{2}$. The maximal current density decreased from 11 to $7.7 \mathrm{~A} \mathrm{~m}^{-2}$ when the bioanode surface area increased from 10 to $100 \mathrm{~cm}^{2}$ because the consumption of the substrate during bioanode reactivation became greater as the electrode surface area increased.

diminished the maximum current density by $30 \%$. This considerable variation was due purely to the consumption of the substrate by the bioanode. It is thus very important to implement a small surface area in a large volume of solution to maintain high substrate concentration. Nevertheless, this precaution is sometimes not sufficient to maintain constant chemical composition when environmental inocula are used because side-reactions due to planktonic microorganisms or sessile microorganisms that are not involved in the electrochemical reaction can also consume large amounts of the substrate.

Finally, it should be noted that, because of the small surface area of the bioanode and the likely presence of side-reactions, a proper electroanalytical cell may result in negligible Faradic yields when complex microbial systems (environmental inocula) are implemented. Assessing Faradic yield or other process yields requires a different cell configuration with large "surface area/ solution volume" ratios. There is thus opposition between the two targets: obtaining a high current density vs. evaluating Faradic or other yields. ${ }^{17}$

\section{Experimental procedures}

\subsection{Experimental set-ups}

Many different architectures of 3-electrode cells have been described in the literature, including single-compartment cells and various dual-compartment configurations such as $\mathrm{H}$-type cells and others. Specific electrochemical cells have been implemented for particular purposes: flow cells to ensure a well-defined hydraulic pattern ${ }^{18}$ or cells equipped with a rotating-disk working electrode to control mass transfer. ${ }^{19}$ If the basic rules are obeyed (see Section 2), in theory, the cell configuration should not matter because it should affect only the potential of the auxiliary electrode and not the potential imposed on the bioanode. For instance, in two-compartment cells, the nature of the separator does not have great importance. A resistive separator can be used, even a proton exchange membrane for instance. It would create a drastic barrier against ion migration at the $\mathrm{pH}$ values around neutrality, at which microbial bioanodes generally operate, but this resistance affects only the potential that the potentiostat must impose on the auxiliary electrode.

Nevertheless, in practice, the cell configuration can indirectly affect the bioanode performance. ${ }^{20}$ The auxiliary electrode (cathode) may reduce oxygen to water, depending on whether the catholyte is oxygenated or not. The reduction of oxygen may also produce hydrogen peroxide. In anoxic conditions, the auxiliary electrode is assumed to produce hydrogen by water reduction:

$$
2 \mathrm{H}_{2} \mathrm{O}+2 \mathrm{e}^{-} \rightarrow 2 \mathrm{OH}^{-}+\mathrm{H}_{2}
$$

Diffusion of oxygen and/or hydrogen peroxide and/or hydrogen (depending on the conditions) from the cathode to the bioanode may affect the performance of the bioanode. Oxygen is an alternative electron acceptor and hydrogen peroxide is detrimental to microbial cells, so both should be detrimental to EA performance. In contrast, hydrogen may favour the enrichment of the bioanode in hydrogenotrophic EA microorganisms. The bioanode could thus become able to oxidise hydrogen in addition to the usual substrate, ${ }^{21-23}$ which may result in an overestimation of the current because of substrate oxidation. 
The bias due to the hydrogen produced can be avoided by sparging the solution with an inert gas $\left(\mathrm{N}_{2}, \mathrm{Ar}\right)$, which continuously removes the hydrogen produced from the cell. Proton exchange membranes, because they are specifically designed to separate hydrogen from oxygen in chemical fuel cells, can also be useful to limit mass transfer to the bioanode in dualcompartment electroanalysis cells. In our opinion, it seems advisable to avoid any unwanted parasite-effects in electroanalytical conditions as far as possible and, if the objective is to assess their impact on the bioanode, to reproduce them in well-controlled conditions by introducing a controlled flow of oxygen, hydrogen peroxide or hydrogen into the anode compartment, rather than letting them occur.

Temperature has a considerable effect on the bioanode kinetics. ${ }^{13}$ It is generally controlled at values ranging from $25{ }^{\circ} \mathrm{C}$ to $40{ }^{\circ} \mathrm{C}$, and up to $70{ }^{\circ} \mathrm{C}$ for sporadic studies on thermophilic EA bacterial species. ${ }^{24}$ The most commonly used value is $30{ }^{\circ} \mathrm{C}$. The anolyte may be stirred or not, and both conditions have been reported. Electroanalysis cells are often protected from light to avoid the possible interaction of phototrophic microorganisms.

The experimental set-ups are not essentially different for studying multispecies communities or pure cultures, except that pure cultures require more experimental care. Reactors must be systematically sterilised for pure cultures, whereas this is rarely the case with environmental inocula. Gases introduced into the cell must be sterile and are often pre-humidified to limit evaporation from the electrochemical cell. The same medium is generally used in both compartments when dual-compartment cells are implemented. In some studies, the reference electrode is separated from the anolyte by a salt bridge. ${ }^{25,26}$

\subsection{Inocula and media}

Environmental inocula. Three main environmental sources of EA microorganisms, wastewater, marine sediments and soils, have been investigated in electroanalysis conditions following two different procedures: either a synthetic medium is inoculated with the inoculum or the environmental sample constitutes both the inoculum and the medium. Acetate is almost unanimously chosen as the substrate, at concentrations ranging from 10 to $25 \mathrm{mM},{ }^{27}$ sometimes up to $40 \mathrm{mM} \cdot{ }^{14,15}$ In a few cases, raw industrial waste has been used without any addition of the substrate. ${ }^{17,28,29}$

Synthetic media for electroanalysis are composed of phosphate buffer solution at $\mathrm{pH}$ from 6.8 to 7.5 and concentrations ranging from 20 to $100 \mathrm{mM}$. The $100 \mathrm{mM}$ concentration has been suggested to be optimal. ${ }^{27}$ Actually, during oxidation of acetate

$$
\mathrm{CH}_{3} \mathrm{COO}^{-}+4 \mathrm{H}_{2} \mathrm{O} \rightarrow 2 \mathrm{HCO}_{3}^{-}+9 \mathrm{H}^{+}+8 \mathrm{e}^{-}
$$

the bioanode undergoes local acidification, which tends to inhibit the metabolic process. ${ }^{27}$ High concentrations of ionic phosphate species enhance the transport of protons out of the biofilm and minimise the impact of biofilm acidification. Ammonium, minerals and sometimes vitamins also compose common synthetic media ${ }^{23,27,30}$ but, obviously, in order to force the EA microorganisms to use the anode as an electron acceptor, no electron acceptor is added. Common constituents of culture media like yeast extract or peptone are sometimes added as nitrogen supply, but they can also be used by the bacteria as $\mathrm{C}$-source and may thus in an uncontrolled manner influence the results of a study. Defined mineral media (with e.g., ammonia as $\mathrm{N}$-source) should be used to avoid this impact. $\mathrm{NaCl}$ may be added to increase the solution conductivity. It has been shown that additions up to $100 \mathrm{mM}$ do not affect some bioanodes. ${ }^{27}$ Synthetic media are generally inoculated with a small fraction (up to $20 \% \mathrm{v} / \mathrm{v}$ ) of environmental inoculum. ${ }^{31}$

In some studies, the purpose was to keep the conditions as close as possible to the environment that the inoculum comes from. Efforts have thus been made to reproduce the natural water/sediment interface, ${ }^{32-34}$ or electrodes have been embedded directly into soils. ${ }^{35-38}$ The use of leachate obtained by percolating a salt solution through a soil sample has led to high current densities. ${ }^{39}$ Industrial effluents, sometimes with minimal supplementation of minerals, have also given interesting results. ${ }^{33,40}$

It should be noted that using raw media or a large amount of environmental inoculum in synthetic medium $(10 \% \mathrm{v} / \mathrm{v}$ or more) has proved to be a source of poor reproducibility, ${ }^{14}$ which may even make the averaging of data impracticable. ${ }^{32}$ Nevertheless, this difficulty should not divert researchers from working in conditions as close as possible to the actual industrial or natural environments in which METs could be implemented. The number of replicates should just be increased and the experimental variations clearly indicated and discussed. Furthermore, the precise location the inoculum is sampled from can also be a source of variation in the bioanode characteristics. ${ }^{33,41}$ The precise place where the inoculum is collected should consequently be accurately indicated in reports.

Pure cultures. Fundamental investigations are recurrently carried out with Geobacter sulfurreducens 1,25,26,42-57 $^{\text {and various }}$ Shewanella species (S. oneidensis, ${ }^{58-65}$ S. putrefaciens, ${ }^{1,2,66,67}$ S. loihica, ${ }^{68-71}$ S. decolorationis, ${ }^{67}$ etc.) used as model strains. Several other microbial species have been investigated in 3 -electrode set-ups but often a single study is reported for each. This is the case for bacteria such as Desulfuromonas acetoxidans, ${ }^{3}$ Aeromonas hydrophila, ${ }^{67}$ Pseudomonas aeruginosa,${ }^{72}$ Propionibacterium freudenreichii, ${ }^{73}$ Rhodoferax ferrireducens, ${ }^{74}$ Acidiphilium sp. ${ }^{75}$ Geothrix fermentans, ${ }^{76}$ Geobacter metallireducens, ${ }^{3}$ Geobacter bremensis, ${ }^{77}$ Geoalkalibacter sp. ${ }^{78}$ Lactococcus lactis, ${ }^{79}$ Rhodobacter capsulatus, ${ }^{80}$ Thermincola ferriacetica, ${ }^{24}$ etc. In recent studies, biotechnologically engineered $G$. sulfurreducens strains have been used to investigate the ET mechanism. ${ }^{81-83}$ The substrate used depends on the affinity/constraints of the strain. Acetate 10 to $20 \mathrm{mM}$ is commonly used with G. sulfurreducens. Lactate is required to grow Shewanella species, generally in concentrations between 10 and $30 \mathrm{mM}$. Glucose has also been used, ${ }^{72-74,79}$ as have other sugars, ${ }^{74}$ benzoate $^{3}$ and, sometimes, ethanol. ${ }^{77}$

One of the main differences with environmental inocula is the careful preparation of the inoculum. Inoculation is often performed with bacterial cells in a well-controlled metabolic state, at the beginning of their stationary growth phase. ${ }^{43,47,49}$ 
Sometimes several successive cultures are performed to obtain optimally active cells. ${ }^{21,25}$ Inocula are often centrifuged and the pellet resuspended in phosphate buffer ${ }^{53,66,73}$ to control the number of cells and to wash away residual electron acceptors. In this way, no dissolved electron acceptor is introduced into the electroanalysis cell. The inoculum ratios are highly variable depending on the objective, from a ratio of $1 / 1500^{72}$ to the complete pre-culture itself (1/1 ratio). ${ }^{49}$ Nevertheless, it has been shown with $G$. sulfurreducens that the ratio of inoculation affects only the lag time needed for colonising the electrode surface and not the final electrochemical performance of the bioanode, essentially because of the absence of inter-species competition for the electrode surface accessibility. ${ }^{25}$

\subsection{Procedures for biofilm formation}

Secondary bioanodes. General speaking, bioanodes always benefit from being formed from a pre-existing EA biofilm. Inoculum is often collected from previous electricityproducing bioanodes. ${ }^{13,27,84-86}$ The formation of the primary bioanode can also serve as a screening method to choose the best sources of inoculum. ${ }^{23}$ Schroeder's group has formed secondary bioanodes by using the whole primary bioanode formed from wastewater to inoculate a fresh reactor. ${ }^{30,87-90}$ The secondary bioanode was produced in a sterilised synthetic medium that was inoculated only with the primary bioanode maintained under the applied potential. ${ }^{91}$ This procedure led to highly reproducible results. ${ }^{11}$ Use of the biofilm scratched from a primary bioanode to form a secondary bioanode, i.e. passing through a step of bacterial suspension, has also been successfully combined with a decrease of the applied potential. An efficient secondary bioanode was thus formed at a potential of $-0.4 \mathrm{~V} / \mathrm{SCE}$, a potential that was too low to form the primary bioanode. ${ }^{40}$ Similarly, feeding the electroanalysis cell with the effluent of an already established MFC has also been implemented. ${ }^{16}$ Inoculating a reactor with a biofilm collected from a previous bioanode has also proved beneficial with pure cultures of G. sulfurreducens ${ }^{48,92}$ (see Section 4.2).

Conversely, it has been observed that a clean electrode put into a medium that has already been used to form a bioanode undergoes faster bioanode formation than the first one. ${ }^{34}$ The residual presence of EA microorganisms or redox mediators in the solution is a likely explanation. It can also be supposed that soluble electron acceptors that were present in the initial solution were depleted during the formation of the primary bioanode.

Batch mode. Electroanalysis studies have been performed in batch, fed-batch, or continuous modes, fed-batch being dominant so far. Fed-batch is often conducted by adding a new dose of the substrate when the current falls near zero, ${ }^{15,67,73}$ or by replacing the whole solution ${ }^{42}$ or a part of the solution. ${ }^{11,58,66,91}$ The presence of the inoculum was necessary in the first batches, then only the fresh medium was used for further replacements. ${ }^{91}$ A different procedure that avoids current decrease by maintaining substrate concentration above a given threshold has sometimes led to higher performance. ${ }^{14,34}$ The two procedures have also been associated, with medium replacement after $24 \mathrm{~h}$ and then successive substrate additions that kept the current near maximum. ${ }^{68}$

Continuous mode. Continuous mode has been implemented with hydraulic residence times of the order of 12 to 20 hours. ${ }^{13,48,52,85}$ Bioanode formation is generally started with the inoculated medium in batch mode ${ }^{43,85}$ or inside a recirculation loop for $24 \mathrm{~h}$ to a few days. ${ }^{52}$ The continuous feeding phase is then performed by providing the reactor with only the medium enriched in the substrate. Continuous mode is particularly interesting because it ensures a stable chemical composition of the anolyte and allows controlled changes in this composition. For instance, the continuous mode has been used to study resting EA biofilms in buffer solution lacking the nutriments required for growth. ${ }^{21}$

Artificial EA biofilms. Artificial EA biofilms are briefly evoked here, although they do not fall within the scope of the present review. Geobacter sulfurreducens cells have been immobilised artificially with pectin on the surface of a graphite anode, leading to an efficient bioanode that generates current immediately after preparation. ${ }^{26}$ So-called "engineered biofilms" have also been designed by immobilising Shewanella oneidensis cells by chemical vapour deposition. ${ }^{93}$ The purple bacterium Rhodobacter capsulatus embedded in an osmium polymer matrix has shown efficient extracellular ET. ${ }^{80}$ These systems open the way to particularly helpful techniques for the routine design of repeatable EA biofilms. They may also provide a means to interference in ET mechanisms by introducing immobilised artificial redox mediators. ${ }^{80}$ In this way they may widen, or divert from depending on the point of view, the field of natural EA biofilms.

\section{Polarisation potential}

\subsection{Applied potential and bioanode performance}

Fig. 3 gives the frequencies with which the different values of the potential have been used to polarise electrodes. The graph displays a fairly symmetrical distribution of potential values centred around a peak at $0 \mathrm{~V} / \mathrm{SHE}$ (around $0.2 \mathrm{~V} v$ s. $\mathrm{Ag} / \mathrm{AgCl}$ or $0.24 \mathrm{~V} / \mathrm{SCE}$ ), which proved to be the most used. In any electrochemical process, the essential practical objective is to design anodes that produce the highest possible current at the lowest possible potential. This preoccupation is clearly visible through the frequency with which low potential values, between -0.6 and $-0.4 \mathrm{~V} / \mathrm{SHE}$, have been used to implement environmental inocula. In contrast, most experiments with pure strains, which have essentially been performed for fundamental purposes, have been carried out between -0.2 and $+0.2 \mathrm{~V} / \mathrm{SHE}$.

Considering the basic rules of electrochemistry, electrodes polarised at high potentials should display higher current densities. However, the reality of microbial bioanodes is more contrasted. Reports can be found that confirm or infirm this assumption, and in fairly balanced numbers. ${ }^{94}$ A clearer overview of this item can be obtained if pure cultures and environmental inocula are differentiated.

Pure cultures. Most studies performed with G. sulfurreducens mention an increase of the current density with the applied 


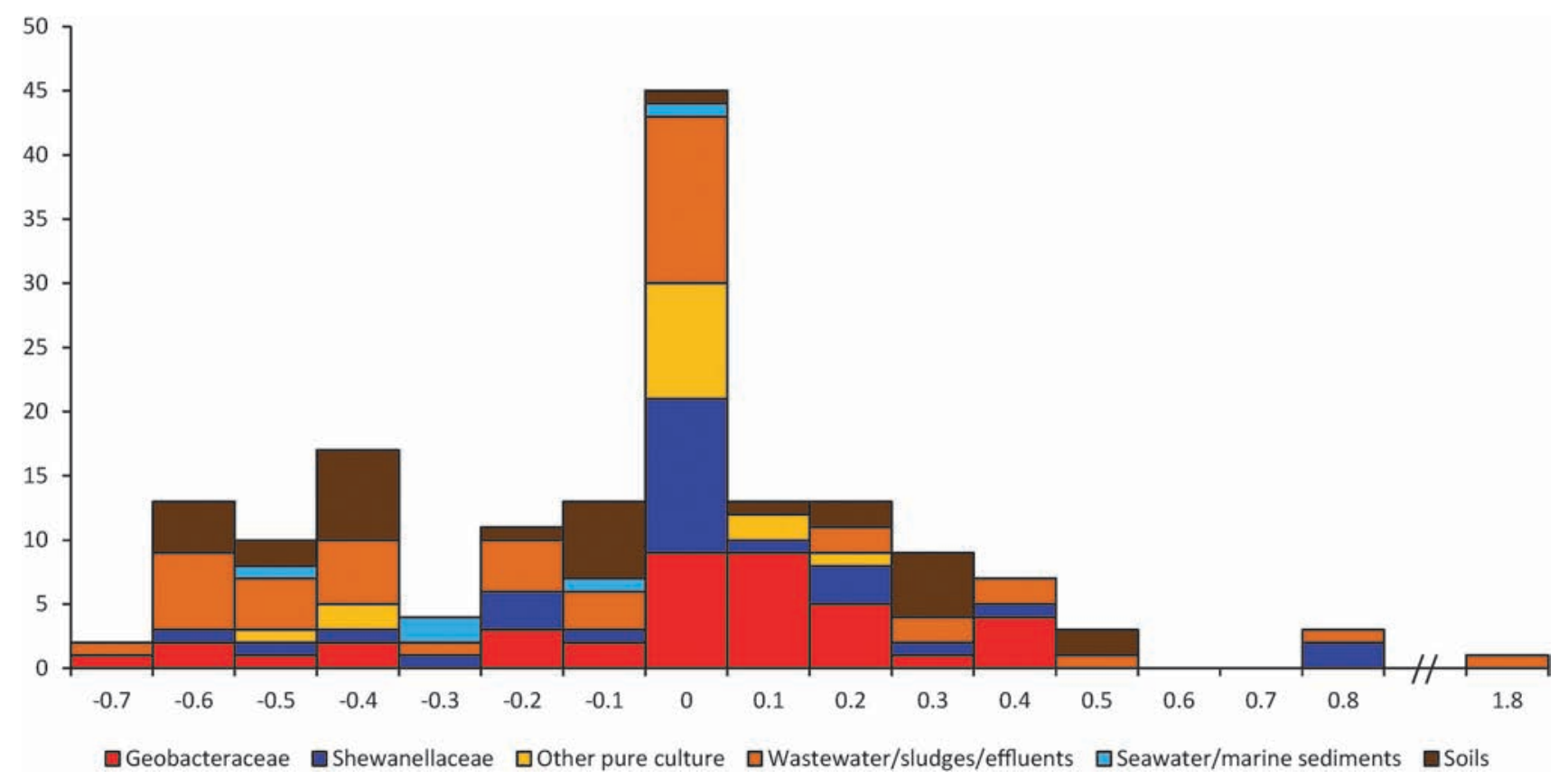

Fig. 3 Occurrences of potential values reported in the literature for the design of microbial anodes under polarisation. Values of the potential used to polarize microbial anodes are presented on the abscissa. They are reported with respect to SHE, by steps of $0.1 \mathrm{~V}$, e.g. potentials between -0.05 and $0.05 \mathrm{~V} / \mathrm{SHE}$ are counted in the $0 \mathrm{~V} / \mathrm{SHE}$ bar. The ordinates indicate the total number of occurrences for each potential value. A total of 112 articles were screened, representing 164 total occurrences of potentials. The histogram gives the number of articles that have used the potential values on the abscissa. Colours are related to the various inocula, classed in six different types.

potential followed by stabilisation at the highest potentials, together with a shorter starting period of bioanode formation. Wide potential ranges have been sampled in various studies $^{42,45,47,49}$ from $-0.67 \mathrm{~V} / \mathrm{SHE}^{42}$ to $0.403 \mathrm{~V} / \mathrm{SHE}^{47}$ A proportional increase of biomass quantity and current density has been evidenced. ${ }^{47}$ A strategy that consisted of forming the biofilm at a fixed applied potential $(0.24 \mathrm{~V} / \mathrm{SHE})$ before gradually shifting it to lower values has shown that the current remains identical down to $-0.06 \mathrm{~V} / \mathrm{SHE}$ and finally declines at $-0.16 \mathrm{~V} / \mathrm{SHE} .^{25}$

Shewanella sp. have shown more contrasted results. S. oneidensis MR-1 ${ }^{60}$ and S. putrefaciens NCTC $10695^{66}$ have led to conclusions similar to those found for G. sulfurreducens: higher current densities, increased quantity of biomass ${ }^{66}$ and diminution in starting time ${ }^{60}$ were observed with higher polarisation potential. However, opposite observations have also been reported with $S$. oneidensis ${ }^{63}$ and $S$. loihica PV4. ${ }^{70}$ The latter study reports an increase of the current up to an applied potential of $47 \mathrm{mV} / \mathrm{SHE}$, then a decrease at higher values. This behaviour was attributed to a switch from a direct to an indirect ET pathway.

Environmental inocula. Bioanodes made from environmental inocula have shown a large variety of behaviours, so it has been difficult to extract a general trend so far. Some bioanodes formed from benthic sediments produced increasing current densities with increasing potentials from 0.14 to $0.815 \mathrm{~V} / \mathrm{SHE}^{32}{ }^{32}$ Similarly, bioanodes formed from effluent collected from a sewage treatment plant showed considerably lower performance when formed at the lowest potential $(-0.67 \mathrm{~V} / \mathrm{SHE}) .{ }^{95}$
Other studies with inocula from an acetate-fed active $\mathrm{MFC}^{96}$ or anaerobic sludge fed with domestic wastewater ${ }^{97}$ have reported the occurrence of an optimal potential, which gave a maximum current compared to lower or higher values. Similarly, bioanodes formed in garden compost gave higher currents at $0.741 \mathrm{~V} / \mathrm{SHE}$ than at lower $(0.541 \mathrm{~V} / \mathrm{SHE})$ or higher $(0.941 \mathrm{~V} / \mathrm{SHE})$ values, ${ }^{36}$ while bioanodes formed in a leachate made from garden compost had potential-independent electrochemical characteristics. ${ }^{39}$ Finally, exactly opposite behaviour has also been experienced with activated sludge used as inoculum: higher current densities, up to $10.3 \mathrm{~A} \mathrm{~m}^{-2}$, and faster microbial colonisation were observed at low potentials $(-0.15$ and $-0.09 \mathrm{~V} / \mathrm{SHE}$ ), while the current did not exceed $0.6 \mathrm{~A} \mathrm{~m}^{-2}$ at $0.37 \mathrm{~V} / \mathrm{SHE}{ }^{85}$ For some studies, it should be noted that the use of drastically high potentials (e.g. $0.941 \mathrm{~V} / \mathrm{SHE}^{36}$ or even $1.803 \mathrm{~V} / \mathrm{SHE}^{98}$ ) may have biased the conclusion. Such high potentials result in oxygen production by water oxidation, which introduces an alternative electron acceptor for aerobic species and can severely affect the anaerobic EA species.

\subsection{Applied potential and adaptation or selection of bacterial strains}

Pure cultures. Bacterial strains have demonstrated a great capacity to adapt to electrochemical conditions by revealing different ET pathways depending on the applied potential. G. sulfurreducens bioanodes have revealed three to seven different redox systems responsible for direct ET depending on the polarisation potential used to form them. ${ }^{25,42,45,49,99}$ These studies come from different research groups and it is not impossible that 
differences in experimental procedures may also have an impact. However, comparisons made by the same research group have also identified the impact of potential: Bulsamen et al. ${ }^{49}$ have observed one redox system centred on $-0.277 \mathrm{~V} / \mathrm{SHE}$ with bioanodes formed at $0.303 \mathrm{~V} / \mathrm{SHE}$, and two others (centred on -0.097 and $0.203 \mathrm{~V} / \mathrm{SHE}$ ) with bioanodes formed at $0.403 \mathrm{~V} / \mathrm{SHE}$. Three other systems were observed by Marsili et al. ${ }^{25}$ centred on $-0.108,-0.056$, and $-0.235 \mathrm{~V} / \mathrm{SHE}$, with the observations being confirmed by Zhu et al., ${ }^{42}$ who also reported four more signals when a larger range of applied potentials was investigated. Moreover, G. sulfurreducens has demonstrated the ability to store and discharge electrons depending on the applied potential as a short-term means of survival. ${ }^{25,43,45}$

A possible adaptation of the G. sulfurreducens strain to electrochemical conditions has been evoked, which resulted in around $450 \mathrm{mV}$ gain for acetate oxidation. ${ }^{54}$ Adaptation of the G. sulfurreducens strain DL1 has also been claimed to result in the KN400 strain with enhanced EA capability. However, Lovley's group has recently demonstrated that, actually, the KN400 strain was a contaminant that was uncovered by the selection pressure of growth on a low-potential electrode: in this case the potential induced selection rather than adaptation. ${ }^{92}$

Shewanellaceae have revealed their ability to exchange electrons either by direct contact with the electrode or via secreted extracellular redox mediators that diffuse in the biofilm. ${ }^{62,63,66,68-70}$ S. loihica PV-4 ${ }^{70}$ and $S$. oneidensis ${ }^{63}$ have been shown to be able to switch from direct ET with the electrode through membranebound cytochromes to indirect ET mediated by extracellular flavins, depending on the applied potential.

Multispecies bioanodes formed from environmental inocula. Environmental inocula contain a wide diversity of microbial species, which may interact with each other, some of them having the capability to become EA on an electrode surface, others not. The polarisation potential can impact these delicate balances between microbial species and it can also affect the ET pathway(s) proper to each EA species. ${ }^{85}$ The effect of the potential is thus considerably more complex on multispecies bioanodes than on pure strains and possible modifications of the electrode surface depending on the potential ${ }^{100}$ may also contribute to increase the discrepancies observed among studies.

Most studies have reported the impact of the applied potential on the selection of particular microbial families, genera or species. Bioanodes formed from activated sludge at $-0.090,0.020$ and $0.370 \mathrm{~V} / \mathrm{SHE}$ have shown great diversity in microbial population, while Geobacter sp. were highly predominant at $-0.150 \mathrm{~V} / \mathrm{SHE} .{ }^{85}$ At high potentials, the electrode had a strong electron acceptor character and supported the growth of numerous different species. At the lower potential, only the microbial species that could set up the most efficient ET pathways were able to grow by taking advantage of the electrode. Another example of stringent selection by low potential has been reported with bioanodes formed from raw paper mill effluents, in which Desulfuromonas acetexigens was the single dominant bacterial species. ${ }^{40}$ In contrast, bioanodes made from garden compost leachate ${ }^{39}$ or wastewater ${ }^{101}$ have, in both cases, revealed identical microbial characteristics whatever the potential used to form them but, even in this case, different ET pathways were identified depending on the potential.

Finally, a recent study using a mixture of soil and activated sludge as inoculum has highlighted the selection of different Geobacter species depending on the applied potential. A strain of $G$. psychrophilus was dominant at $-0.46 \mathrm{~V} / \mathrm{SHE}$, and was genetically different from the strains that dominated the -0.42 and $-0.36 \mathrm{~V}$ bioanodes. ${ }^{102}$ Another major feature of this article was to demonstrate the difficulty of drawing universal conclusions on this topic. Actually, when just a few operating parameters were changed (batch $v s$. continuous feeding, temperature, phosphate buffer concentration, nitrogen sparging or not) the same inoculum with the same procedure performed by the same experimenters led to completely different bacterial communities that were no longer dominated by Geobacter species. A few secondary parameters can drastically affect the composition of the bacterial communities that develop on bioanodes.

\subsection{Applied potential and interactions in co-cultures}

Co-cultures have so far been poorly investigated in the MFC field. A review from 2010 listed only 3 articles. ${ }^{103}$ Some clever experimental MFC set-ups have been developed to increase the number of replicates and improve repeatability ${ }^{104}$ and a few studies have been carried out under potential-control in 3-electrode set-ups. Substrate-based relationships have been identified between S. oneidensis and Lactococcus lactis $^{105}$ or G. sulfurreducens and Pelobacter carbinolicus, ${ }^{106}$ one strain using the compound(s) produced by the other, while metabolite-based mutualism has been uncovered between Pseudomonas aeruginosa and Enterobacter aerogenes. ${ }^{107}$ In this framework, a recent comment about a possible syntrophy in MFC has emphasised the interest of working under potential-control and of checking different potentials to increase the significance of the results. ${ }^{10}$

\section{Electroanalytical techniques}

\subsection{Chronoamperometry to form bioanodes}

Bioanode formation under chronoamperometry is almost universally carried out at a constant applied potential. Only rare studies have attempted to form bioanodes with potential changes, ${ }^{25,40,95}$ or with a first phase at open circuit before establishing the polarisation. ${ }^{108,109}$ Bioanodes formed in arctic soils have shown similar microbial communities on the biofilms that developed at open circuit or under polarisation $(0.1 \mathrm{~V} / \mathrm{SHE})^{107}$ but microbial colonisation was considerably lower at open circuit for bioanodes formed from marine sediments $(0.14 \mathrm{~V} / \mathrm{SHE})^{33}$ or garden compost $(0.04 \mathrm{~V} / \mathrm{SHE}) .{ }^{108}$

A few studies have addressed the first phase of EA biofilm formation with G. sulfurreducens. Clear differences have been revealed in the composition of the outer-surface cytochromes ${ }^{110}$ and in the extracellular ET rates ${ }^{25}$ between the fumarate-respiring cells that initially colonise the anode surface and the cells that finally respire the anode. The transition from a fumaraterespiring metabolism to an anode-respiring mechanism in the early formation of biofilm has been further confirmed. ${ }^{111}$ 
Investigations of the dynamics of G. sulfurreducens bioanodes after short interruptions of the polarisation potential have led to an accurate description of the distribution of the intracellular and extracellular cytochromes. ${ }^{112}$

In batch mode, after establishment of the EA biofilm, the current decreases due to depletion of the substrate (Fig. 2). Adding a new dose of the substrate or refreshing the medium results in a progressive recovery of the current, which can take several hours. The current recovery is too slow to be controlled by the mass transfer rate of the substrate. It may be thought that cells undergo de-activation or die during starvation, which then requires partial re-activation or re-construction for the bioanode capabilities to be restored. The kinetics of current recovery after substrate depletion has not yet been addressed to our knowledge but it undoubtedly warrants specific investigation.

\subsection{Voltammetries}

Cyclic voltammetry (CV) has been widely used when the objective is to advance in deciphering ET mechanisms. CV experiments are generally performed in the absence of a substrate (non-turnover conditions) in order to observe the redox compounds confined inside the biofilm. ${ }^{99}$ In theory, each redox compound that is electrochemically accessible to the electrode is oxidised and then reduced during the backward and forward scans, which results in one pair of oxidation and reduction current peaks (Fig. 4A). The results concerning the different redox systems discussed in Section 4 were extracted from such CV. Great advances have recently been achieved in understanding the ET pathways by associating CV with genetically/metabolically engineered $G$. sulfurreducens strains. ${ }^{81-83}$

Cyclic voltammetry performed when the substrate is present in solution, so-called "catalytic" CV, generates typical sigmoidalshape voltammograms showing a potential-independent maximum current at high potentials (Fig. 4B). The limiting catalytic current is not necessarily controlled by the diffusion of the substrate. The impact of the various possible limiting factors, acetate diffusion to the cells, proton extraction from the biofilm, electron transport inside the biofilm, and metabolic rate, has been analysed in depth with a $G$. sulfurreducens bioanode by associating a rotating disk electrode with the numerical interpretation of the data. ${ }^{19}$

The most common objective of catalytic CV is to assess the performance of bioanodes at steady-state. This is the reason why low scan rates are used, most often around $1 \mathrm{mV} \mathrm{s}^{-1}$. Occasionally, slower scan rates can be found. ${ }^{70}$ Transient CV in catalytic conditions has been rarely exploited so far, although it should be a powerful tool for fundamental investigations. For instance, a high potential scan rate $\left(100 \mathrm{~V} \mathrm{~s}^{-1}\right)$ used with a Shewanella bioanode in catalytic conditions has allowed the contribution of the outer-membrane cytochromes to be clearly evidenced. ${ }^{113}$ Bioanodes formed from garden compost leachate have given $\mathrm{CV}$ curves that remained identical to the stationary curve when the scan rate was increased from 1 to $100 \mathrm{mV} \mathrm{s}^{-1} \cdot{ }^{114}$ According to a recent theoretical model, ${ }^{99}$ this behaviour reveals a high rate of electron extraction from
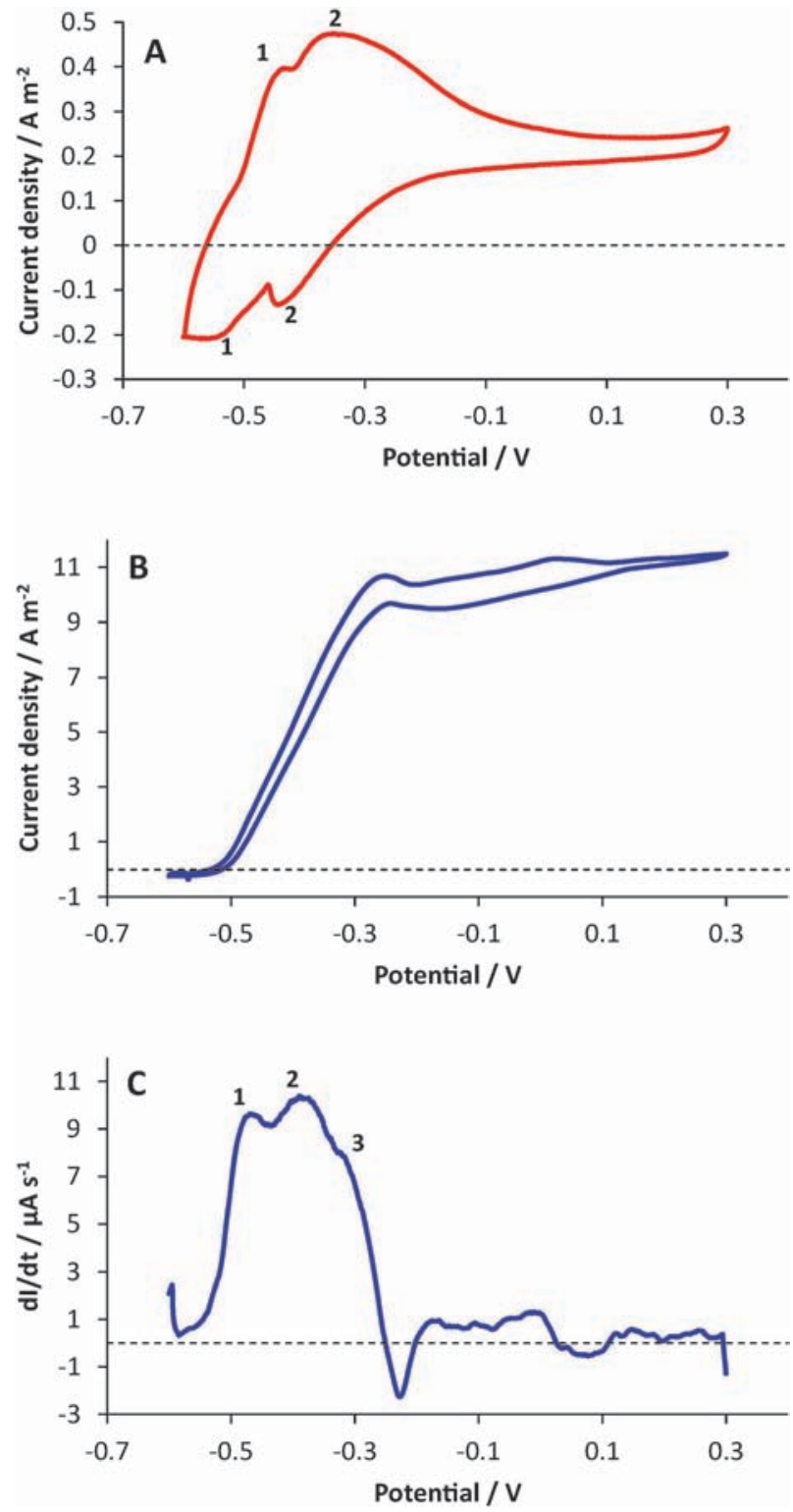

Fig. 4 Cyclic voltammograms (scan rate $1 \mathrm{mV} \mathrm{s}^{-1}$ ) obtained in catalytic ( $B$, blue) and non-turnover ( $A$, red) conditions together with the first derivative of the catalytic CV forward scan (C, blue) obtained with a bioanode formed at $-0.2 \mathrm{~V} / \mathrm{SCE}(0.014 \mathrm{~V} / \mathrm{SHE})$ in hydrolysed biological sludge. Two signals corresponding to two distinct redox species (denoted 1 and 2) are distinguishable on the non-turnover $C V$, whereas a single signal dominates on catalytic CV. The calculation of the first derivative of the catalytic CV forward scan helps to discern the two signals identified under non-turnover condition and melted in the catalytic one, and a third one identified by the number 3 .

the cells compared to the rate of electron transport through the biofilm.

In 2008, Torres et al. combined the Nernst law with a Monod equation to obtain the Nernst-Monod equation ${ }^{13}$ that fits catalytic CV well when the ET rate at the biofilm/electrode interface is fast and reversible. ${ }^{39}$ For non-reversible ET rates, the Butler-Volmer-Monod equation was developed by Hamelers et al. in 2011. ${ }^{16}$ Lovley's and Tender's groups ${ }^{115,116}$ have developed a 
theoretical model organised in 5 steps: (1) mass transfer of the substrate/product (Fick diffusion), (2) metabolic reactions (Michaelis-Menten-type kinetics), (3) electron release from the cell to the biofilm network (pseudo first-order kinetics), (4) electron transport in the biofilm (diffusion-like process), and (5) reversible ET at the electrode surface (Nernst equilibrium). This model seems to be widely used now ${ }^{19,112,117}$ and has recently been extended to a transient approach. ${ }^{118}$

The association of numerical modelling with CV and possibly other coupled technique(s) will undoubtedly be a factor of fast fundamental advances. For example, a current hot topic is the actual role of bacterial pili in electron transport inside EA biofilms with two different points of view: ${ }^{119-122}$ pili may be electrical nanowires with metallic-like conductivity or electron transport may be ensured by successive electron hopping between adjacent cytochrome molecules aligned along the pili. CV implemented with a rotating disk electrode and combined with a numerical model has recently afforded helpful new information that differentiates the possible role of each pathway. $^{19}$

From a practical point of view, due to their complexity and the occurrence of high capacitive currents at fast scan rates, CVs obtained with microbial bioanodes often need preliminary treatment before analysis. Background current subtraction and removal of the capacitive contributions ${ }^{62,66,113}$ or first derivative analysis ${ }^{25,45,66,68,69,71,99}$ may help in discriminating redox reactions that can occur at close potentials. This last analysis is particularly useful for catalytic CV, as it allows the separation of redox signals that are confounded within the catalytic wave. ${ }^{45,99}$ Marsili's group has commonly used differential pulse voltammetry to better identify the different redox systems. ${ }^{25,62,68,69,71}$ This method gives a more direct reading of the peak potentials compared to conventional $\mathrm{CV}$ and is more sensitive for the detection of mediators.

\subsection{Electrochemical impedance spectroscopy (EIS)}

EIS has been widely used to characterise complete microbial electrochemical reactors (MFC and MEC) and the bioanodes included in them (see a recent review on EIS applied to bioelectrochemical systems ${ }^{123}$ ). In contrast, the use of EIS coupled with electroanalysis set-ups is less frequent. EIS has been implemented to characterise anodes covered by artificial biofilms made of G. sulfurreducens cells immobilised by pectin. ${ }^{26}$ EIS has also demonstrated that the presence of electrodeposited carbon nanotubes on the graphite surface improves the charge transfer rate in $S$. loihica-PV4 bioanodes. ${ }^{71}$ Bioanodes formed under polarisation $(0.410 \mathrm{~V} / \mathrm{SHE})$ or directly in an MFC have been compared, showing a lower resistance of the bioanode formed under a constant potential. ${ }^{31}$

\subsection{Spectroelectrochemistry}

The most sophisticated electroanalysis cells combine the electrochemical analysis capability with in situ spectroscopy. Spectroelectrochemistry has provided powerful techniques in the field of protein bioelectrochemistry ${ }^{124,125}$ and has started to be implemented by different research groups for the analysis of G. sulfurreducens and Shewanella sp. bioanodes, as reviewed recently. ${ }^{126}$

Spectroelectrochemistry techniques often require the use of specific and well-characterized electrode materials. UV/visible spectroscopy needs transparent electrodes and is generally implemented with a thin layer of indium tin oxide (ITO) deposited on glass. ${ }^{69,127,128}$ The spectroscopic analysis is recorded through the biofilm and gives information averaged across its entire thickness. In contrast, attenuated total reflection (ATR) surface enhanced infrared absorption spectroscopy (SEIRAS) focuses on bacterial molecules in direct contact with the electrode surface. This technique uses a thin-film gold electrode to analyse the reflection of an IR beam that is projected onto the rear side of the electrode (the side that does not support the biofilm)..$^{55,57,129}$ Self-assembled monolayer Raman spectroscopy (surface-enhanced resonance Raman) has been implemented with silver electrodes, ${ }^{129}$ in some cases with an enhanced appropriate roughness. ${ }^{130}$ The rough silver electrode led to current densities similar to those obtained on graphite. The method targeted the outer-membrane cytochromes that are confined in the close vicinity of the electrode surface $(<7 \mathrm{~nm})$.

Confocal Raman spectroscopy can avoid the requirement for specific electrode material. The technique has enabled the noninvasive characterisation of a multispecies biofilm grown on a graphite electrode. ${ }^{56}$ The great advantage here was that a graphite electrode could be used, but the spectroscopic measurement was ex situ and not in real-time because the electrode had to be extracted from the electrochemical cell for the spectroscopic measurement.

\section{Electrode materials (Table 1)}

\subsection{Carbon-based materials, DSA and stainless steel: materials for engineering}

When the objective is to design bioanodes, carbon-based materials have been almost unanimously preferred, as reviewed in several articles. ${ }^{47,139-141}$ Other industrial-type materials, including stainless steel and dimensionally stable anodes (DSA, metallic oxides on a titanium support), have been little investigated so far, even though some comparisons have suggested that stainless steel and DSA can lead to performance comparable to that of carbon. ${ }^{33,50,109,114}$

Carbon-based materials, including both graphite and amorphous carbon, are easy to handle and easy to procure from various suppliers. They can be produced in the laboratory from natural (e.g. pomelo peel ${ }^{135}$ ), easy-to-find sources ${ }^{11}$ and can be given well-controlled three-dimensional shapes. ${ }^{87,88}$ Borondoped diamond (BDD) electrodes have also been attempted. ${ }^{142}$ Almost all studies comparing the suitability of different electrode materials to form bioanodes have been carried out in complete reactors (MFC, MEC), where it is likely that the bioanode is not the only rate-limiting step. Considering also the difference in experimental conditions from one work to the other, the data coming from different reports can hardly be compared. 
Table 1 Anode materials studied at fixed potentials

\begin{tabular}{|c|c|c|c|}
\hline Material & Structure & Electrode potential & Inoculum \\
\hline Boron-doped diamond & Nanostructured & $0.2 \mathrm{~V} / \mathrm{Ag}-\mathrm{AgCl}$ & S. loihica $\mathrm{PV}-4^{131}$ \\
\hline \multirow[t]{11}{*}{ Carbon } & Plate & $\begin{array}{l}0.2 \mathrm{~V} / \mathrm{SCE} \\
-0.46 \text { to } 0.6 \mathrm{~V} / \mathrm{Ag}-\mathrm{AgCl} \\
0.2 \mathrm{~V} / \mathrm{Ag}-\mathrm{AgCl} \\
0.2 \mathrm{~V} / \mathrm{Ag}-\mathrm{AgCl} \\
-0.3 \mathrm{~V} / \mathrm{Ag}-\mathrm{AgCl} \\
0.3 \mathrm{~V} / \mathrm{Ag}-\mathrm{AgCl} \\
-0.26 \text { to } 0.26 \mathrm{~V} / \mathrm{NHE} \\
-0.24 \text { and } 0.0 \mathrm{~V} / \mathrm{SCE} \\
-0.1 \mathrm{~V} / \mathrm{SCE} \\
0.2 \mathrm{~V} / \mathrm{Ag}-\mathrm{AgCl} \\
0.2 \mathrm{~V} / \mathrm{Ag}-\mathrm{AgCl}\end{array}$ & $\begin{array}{l}\text { G. } \text { subterraneus }^{132} \\
\text { G. } \text { sulfurreducens }^{42} \\
\text { S. }{\text { loihica } \text { PV-4 }^{68,69}}_{\text {Wastewater }^{87}} \\
\text { Wastewater }^{16} \\
\text { G. } \text { sulfurreducens }^{116} \\
\text { G. } \text { sulfurreducens }^{25} \\
\text { S. } \text { oneidensis }^{63} \\
\text { Seawater biofilm }^{33,109} \\
\text { Wastewater }^{31} \\
\text { G. } \text { sulfurreducens }^{21}\end{array}$ \\
\hline & Rod & $\begin{array}{l}-0.06 \mathrm{~V} / \mathrm{SHE} \\
-0.2 \mathrm{~V} / \mathrm{Ag}-\mathrm{AgCl} \\
0.2 \mathrm{~V} / \mathrm{Ag}-\mathrm{AgCl} \\
-0.1 \text { to } 0.4 \mathrm{~V} / \mathrm{Ag}-\mathrm{AgCl} \\
-0.4 \text { to } 0.2 \mathrm{~V} / \mathrm{SHE} \\
0.2 \mathrm{~V} / \mathrm{Ag}-\mathrm{AgCl} \\
0.2 \mathrm{~V} / \mathrm{Ag}-\mathrm{AgCl} \\
-0.4 \text { to } 0.2 \mathrm{~V} / \mathrm{Ag}-\mathrm{AgCl} \\
-0.15 \text { to } 0.37 \mathrm{~V} / \mathrm{SHE} \\
0.1 \text { to } 0.6 \mathrm{~V} / \mathrm{Ag}-\mathrm{AgCl} \\
0.2 \mathrm{~V} / \mathrm{Ag}-\mathrm{AgCl} \\
-0.35 \mathrm{~V} / \mathrm{Ag}-\mathrm{AgCl}\end{array}$ & 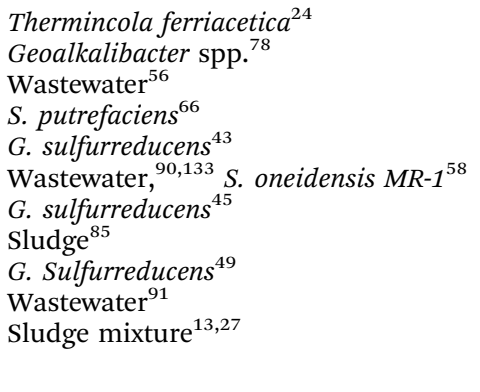 \\
\hline & Paper & $\begin{array}{l}0.2 \mathrm{~V} / \mathrm{Ag}-\mathrm{AgCl} \\
0.3 \mathrm{~V} / \mathrm{Ag}-\mathrm{AgCl} \\
-0.16 \text { to } 0.4 \mathrm{~V} / \mathrm{NHE} \\
0.24 \mathrm{~V} / \mathrm{SHE}\end{array}$ & $\begin{array}{l}\text { S. oneidensis }{ }^{61} \\
\text { P. aeruginosa } \\
\text { G. } \text { sulfurreducens }^{47} \\
\text { G. } \text { sulfurreducens }^{26}\end{array}$ \\
\hline & Fibers/cloth & $\begin{array}{l}-0.2 \mathrm{~V} / \mathrm{SCE} \\
0.2 \mathrm{~V} / \mathrm{Ag}-\mathrm{AgCl} \\
0.2 \mathrm{~V} / \mathrm{Ag}-\mathrm{AgCl} \\
0.3 \mathrm{~V} / \mathrm{Ag}-\mathrm{AgCl} \\
0.44 \mathrm{~V} / \mathrm{SHE}\end{array}$ & $\begin{array}{l}\text { Compost leachate }^{108} \\
\text { Wastewater }^{87,88} \\
\text { Wastewater }^{89} \\
\text { P. aeruginosa/E. } \text { aerogenes }^{107} \\
\text { S. oneidensis }{ }^{59}\end{array}$ \\
\hline & Felt & $\begin{array}{l}0.2 \mathrm{~V} / \mathrm{SCE} \\
-0.1 \mathrm{~V} / \mathrm{SCE} \\
0.2 \mathrm{~V} / \mathrm{Ag}-\mathrm{AgCl} \\
0.1 \mathrm{~V} / \mathrm{SCE} \\
0.1 \mathrm{~V} / \mathrm{SHE} \\
0.4 \mathrm{~V} / \mathrm{Ag}-\mathrm{AgCl}\end{array}$ & 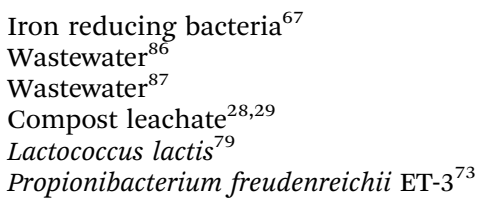 \\
\hline & Mesh & $0.3 \mathrm{~V} / \mathrm{Ag}-\mathrm{AgCl}$ & G. sulfurreducens ${ }^{53}$ \\
\hline & Granules & $\begin{array}{l}-0.2 \mathrm{~V} / \mathrm{Ag}-\mathrm{AgCl} \\
-0.4 \text { to } 0.0 \mathrm{~V} / \mathrm{Ag}-\mathrm{AgCl}\end{array}$ & $\begin{array}{l}\text { Activated sludge } \\
\text { Wastewater }^{134}\end{array}$ \\
\hline & Brush & -0.4 to $0.2 \mathrm{~V} / \mathrm{Ag}-\mathrm{AgCl}$ & Wastewater ${ }^{84}$ \\
\hline & Foam & $0.2 \mathrm{~V} / \mathrm{Ag}-\mathrm{AgCl}$ & Wastewater $^{135}$ \\
\hline & 3D KSC & $0.2 \mathrm{~V} / \mathrm{Ag}-\mathrm{AgCl}$ & Wastewater ${ }^{136}$ \\
\hline & Corrugated cardboard & $0.2 \mathrm{~V} / \mathrm{Ag}-\mathrm{AgCl}$ & Wastewater $^{11}$ \\
\hline Dimensionally stable anode (DSA) & Plate & $\begin{array}{l}0.5 \mathrm{~V} / \mathrm{SCE} \\
-0.1 \mathrm{~V} / \mathrm{SCE} \\
0.2 \mathrm{~V} / \mathrm{Ag}-\mathrm{AgCl} \\
0.5 \mathrm{~V} / \mathrm{SCE}\end{array}$ & $\begin{array}{l}\text { Geobacter bremensis }{ }^{77} \\
\text { Seawater biofilm } \\
\text { G. } \text { sulfurreducens }^{50} \\
\text { Garden compost }^{35,36}\end{array}$ \\
\hline Gold & Bare & $0.4 \mathrm{~V} / \mathrm{Ag}-\mathrm{AgCl}$ & G. sulfurreducens ${ }^{129}$ \\
\hline & Interdigitated $\mu$-array & $0.3 \mathrm{~V} / \mathrm{Ag}-\mathrm{AgCl}$ & G. sulfurreducens ${ }^{137}$ \\
\hline & Plate wafer & $0.24 \mathrm{~V} / \mathrm{SHE}$ & S. oneidensis ${ }^{138}$ \\
\hline & Line array & $0.24 \mathrm{~V} / \mathrm{SHE}$ & G. sulfurreducens ${ }^{46}$ \\
\hline
\end{tabular}


Table 1 (continued)

\begin{tabular}{|c|c|c|c|}
\hline Material & Structure & Electrode potential & Inoculum \\
\hline & Ultraflat surface & $0.3 \mathrm{~V} / \mathrm{Ag}-\mathrm{AgCl}$ & G. sulfurreducens ${ }^{52}$ \\
\hline \multirow[t]{2}{*}{ Indium tin oxide (ITO) } & Sheet & $\begin{array}{l}0.0 \mathrm{~V} / \mathrm{SCE} \\
0.2 \mathrm{~V} / \mathrm{Ag}-\mathrm{AgCl}\end{array}$ & $\begin{array}{l}\text { S. loihica } \mathrm{PV}-4^{69} \\
\text { G. sulfurreducens }{ }^{128}\end{array}$ \\
\hline & Plate & $0.2 \mathrm{~V} / \mathrm{Ag}-\mathrm{AgCl}$ & S. oneidensis $\mathrm{MR}-1^{113}$ \\
\hline Platinum & $\begin{array}{l}\mu \text { Wire } \\
\text { Wire }\end{array}$ & $\begin{array}{l}-0.2 \mathrm{~V} / \mathrm{SCE} \\
-0.4 \mathrm{~V} / \mathrm{Ag}-\mathrm{AgCl}\end{array}$ & $\begin{array}{l}\text { Compost leachate }{ }^{117} \\
\text { G. sulfurreducens }{ }^{48}\end{array}$ \\
\hline Silver & Roughened plate & $0.2 \mathrm{~V} / \mathrm{Ag}-\mathrm{AgCl}$ & Wastewater ${ }^{126,130}$ \\
\hline \multirow[t]{3}{*}{ Stainless steel } & $\mu$ Wire & $-0.3 \mathrm{~V} / \mathrm{SCE}$ & Drinking water ${ }^{37}$ \\
\hline & Plain & $\begin{array}{l}-0.1 \mathrm{~V} / \mathrm{SCE} \\
-0.1 \mathrm{~V} / \mathrm{SCE} \\
-0.2 \mathrm{~V} / \mathrm{SCE}\end{array}$ & $\begin{array}{l}\text { Seawater biofilm } \\
\text { G. sulfurreducens }{ }^{31} \\
\text { Compost leachate }\end{array}$ \\
\hline & Mesh & $-0.1 \mathrm{~V} / \mathrm{SCE}$ & Seawater biofilm ${ }^{109}$ \\
\hline
\end{tabular}

Some trends can be extracted from the studies that have compared different materials in 3-electrode set-ups under identical conditions. A comprehensive comparison of graphite rod, polycrystalline carbon rod, carbon fibre veil, and graphite foil performed under polarisation at $0.197 \mathrm{~V} / \mathrm{SHE}$ has concluded that a geometric structure favourable to microbial colonisation (active surface, porosity, etc.) seems to be a much more important parameter than the nature of the carbon material itself (amorphous, crystalline, purity, etc.). ${ }^{87}$ These results were obtained with multispecies bioanodes formed from wastewater. Bioanodes formed from pure cultures of G. sulfurreducens have led to similar observations. Similar current densities, around $5 \mathrm{~A} \mathrm{~m}^{-2}$, were obtained with both graphite and DSA, and the current densities were correlated with the biofilm quantity, which depended on the surface roughness of each electrode. ${ }^{50}$ A similar relationship between current density and surface roughness has been pointed out for graphite and DSA inoculated with a marine inoculum. ${ }^{33}$ Nevertheless, recent results tend to restrict the effect of surface roughness to young, thin EA biofilms only, whereas mature bioanodes are covered by uniform biofilms several tens of micrometres thick, which masks the effect of the electrode topography. ${ }^{114}$

\subsection{Platinum, gold, silver, indium tin oxide: materials for understanding}

Platinum, gold, silver and indium tin oxide have several advantages over carbon-based materials for fundamental investigations. Their high electronic conductivity and low double-layer capacitance limit the residual currents and increase the sensitivity of the electrochemical measurements. They can be deposited in the form of thin films on a variety of materials through chemical or physical vapour techniques. Their surface state and topography can generally be perfectly mastered, chemically or electrochemically treated, and structured at the micro- or even nanometre scale.

Indium tin oxide (ITO). ITO electrodes have been widely used in the field of protein electrochemistry, particularly for investigating cytochrome $C .{ }^{143}$ They have thus logically been used in the domain of microbial anodes firstly to perform spectroelectrochemical analysis of cytochrome C552 in biofilms of G. sulfurreducens. ${ }^{128}$ Microbial colonisation of an ITO surface is low. Cell-electrode interactions can thus be investigated with mature biofilms that remain thin, generally a single layer of adsorbed cells. This is a clear advantage if the objective is to work with a well-defined biofilm amount and structure. Nevertheless, the nature of the surface may affect the ET mechanisms. When grown on ITO, Shewanella loihica PV-4 exchanges electrons with the electrode only via direct ET, while on graphite or other carbon based electrodes, $S$. loihica combines direct and indirect ET. ${ }^{69}$ This example emphasises the considerable role that the nature of the electrode material can play in the adaptation of EA cells to electrode-respiring mechanisms.

The raw surface of gold does not seem to be suitable for developing bioanodes with Shewanella sp. because of unfavourable interaction with the molecules involved in indirect ET. ${ }^{52}$ Nevertheless, the high quality of the electroanalytical measurements that gold permits can make its use worthwhile, at the cost of some experimental sophistication, such as using genetically engineered Shewanella cells to promote their adhesion. ${ }^{138}$ Surface modification by a functionalised self-assembled monolayer has allowed the formation of $S$. putrefaciens bioanodes providing electrochemical performance levels similar to those obtained on graphite, ${ }^{144}$ but membrane-electrode interactions were suspected to have a denaturing effect on the outer membrane cytochromes involved in direct ET.

Regarding G. sulfurreducens bioanodes, gold electrodes have led to results almost identical to those with graphite. EA biofilms of $40 \mu \mathrm{m}$ thickness were obtained on flat gold electrodes, in which ET was mainly achieved via conductive pili. ${ }^{52,115}$ Gold has also been used to introduce the concept of zero-charge potential in the description of the early phase of formation of a Pseudomonas fluorescens bioanode. ${ }^{18}$ Interdigitated gold microelectrode arrays have been implemented to study the longrange electron transport in G. sulfurreducens biofilms. ${ }^{46}$ 
Platinum, like gold, is known to achieve fast ET with biological redox compounds, including cytochromes ${ }^{145}$ and other redox biological mediators, ${ }^{146}$ but it has rarely been used in the field of microbial anodes. ${ }^{48,117}$

\subsection{Electrode structure can considerably increase current densities}

Flat-surface electrodes and a variety of two- and three-dimensional structures (cloth, felt, foam, brush, etc.) have been tested with carbon materials (Table 1). The suitability of the different structures and shapes for forming microbial bioanodes can hardly be compared because their performance has been described in different studies, often using different inocula, with different anode configurations and at different applied potentials. Nevertheless, a few data can be recalled to sketch a general framework.

It seems to be widely agreed that current density around $10 \mathrm{~A} \mathrm{~m}^{-2}$ is the maximum level that bioanodes could reach on flat electrode surfaces (see Chen et al. ${ }^{87}$ and references therein). Flat stainless steel has produced up to $20 \mathrm{~A} \mathrm{~m}^{-2}$ in compost leachate, ${ }^{114}$ but these data must be qualified because the two sides of the electrode were exposed to the solution while the current density was calculated with respect to the projected surface area, i.e. one side only. Nevertheless, recent experiments have revived the hope of pushing this maximum upwards: in pure culture of $G$. sulfurreducens, flat graphite has generated more than $15 \mathrm{~A} \mathrm{~m}^{-2} \cdot{ }^{42,54}$ The maximum current density reached on flat electrodes ( $66 \mathrm{~A} \mathrm{~m}^{-2}$ ) was obtained by growing multispecies EA biofilms around platinum ultra-microelectrodes. It was stated that the ultra-microelectrode effect that occurred at electrode diameters of less than $50 \mu \mathrm{m}^{147}$ improved the ET capability of the biofilm matrix. ${ }^{117}$

Current densities are usually expressed with respect to the projected (geometric) surface area and are thus boosted by any electrode structure that offers a large active surface area to be colonised by the biofilm. The structure must allow the microorganism to penetrate as deeply as possible and be sufficiently open to avoid clogging by mature biofilms. ${ }^{11,135,148}$ Carbon felt and other macroporous structures with high porosity are fairly successful in meeting these criteria, giving maximum current density of the order of 30 to $35 \mathrm{~A} \mathrm{~m}^{-2}$ when inoculated with wastewater $^{87-89}$ or compost leachate ${ }^{114}$ and up to $85 \mathrm{~A} \mathrm{~m}^{-2}$ with salt marsh sediment. ${ }^{14}$ Finally, a particular multilayered electrode architecture has allowed $390 \mathrm{~A} \mathrm{~m}^{-2}$ to be reached with wastewater as inoculum. ${ }^{11}$ All these current densities have been obtained with the addition of a substrate, generally acetate at concentrations of 10 to $40 \mathrm{mM}$. When real raw media are used without any addition of the substrate, current densities are lower, around a few $\mathrm{A} \mathrm{m}^{-2} \cdot{ }^{17,28,29}$

\section{Outlook}

From an engineering point of view, working in electroanalysis conditions has led to a rapid increase in current densities (see Section 6.3). Rigorous control of the electrochemical parameters has saved the bioanodes from the detrimental interactions that they undergo in MFCs and so has shown their real efficiency. Efforts are still needed to standardise the calculation of the current density so that performance can be better compared among reports. Using flat electrodes in a welldesigned configuration (see Section 2.2) appears to be an ideal solution for analytical purposes, but a basic theoretical approach is still needed to compare sophisticated electrode configurations.

Graphite and other carbon-based materials have received an almost unanimous plebiscite and an exceedingly large variety have been used (Table 1). If large-scale industrial applications are to be developed, industrial materials such as stainless steel and DSA should not been neglected (see Section 6.1). Most studies report the maximum current density provided with one material at one working potential. Comparisons of materials should now turn more systematically towards kinetics. For instance, some materials (stainless steel, ${ }^{114}$ carbon $^{87}$ ) can provide high current density at high potentials but with slow nonNernstian interfacial ET, while some carbon electrodes ensure Nernstian ET but lower current density at high potentials. ${ }^{39}$ In the first case, improvements can be made by improving the interfacial ET rate, and in the second case this step is already fast enough and research efforts need to be focused elsewhere. It is now time to compare materials in terms of kinetics in order to identify the methods most likely to progress on this item, i.e. current-potential curves should be presented rather than just maximal current density values.

From a fundamental point of view, great advances have been achieved in deciphering the ET transfer pathways with the model strains Geobacter sulfurreducens and Shewanella sp. Fundamental understanding of multispecies bioanodes is considerably less advanced. Electroanalysis is just starting to be coupled with fine characterisation of the microbial communities. The recent possibility of implementing DNA pyrosequencing at a fairly reasonable cost should boost the indispensable association of physical and biological analytical techniques. A recent study has evidenced exceedingly high versatility in wild bioanodes, which, in our opinion, was previously unsuspected. ${ }^{102}$ Consequently, it seems essential to fix as many parameters as possible and to use set-ups that are as simple as possible. For instance, studies aiming at fundamental advances should be differentiated from the legitimate race to the highest current densities. The latter requires sophisticated three-dimensional electrodes, while the former should lead to more accurate conclusions with flat and morphology-controlled electrodes. On flat electrodes, electrochemical techniques, and particularly impedance spectroscopy, can deploy all their analytical power. Actually, when implementing EIS, care should be taken to use a physical representation of the interface that makes sense globally and to check that the value of each parameter makes sense individually. In this objective, it is essential to implement EIS in as simple an experimental set-up as possible. Obviously co-cultures, which have not been widely exploited so far (see Section 4.3), should be an ideal gateway to the in-depth deciphering of the complex relationships that occur in multispecies EA biofilms. 


\subsection{Combining analytical techniques and theoretical modelling}

Any possible combination of different electroanalytical techniques may be interesting to contemplate. For example, microsystem technologies should be able to provide specifically designed (ultra-)microelectrodes to address specific questions at the microsize level within biofilms or to perform electroanalysis at cell size. Like others, this domain has only been touched upon so far; yet microelectrodes would be the right tool for approaching the sharp spatial heterogeneities of bioanodes. Atomic force microscopy (AFM) and scanning tunnelling microscopy (STM) have already been used to investigate pili extracted from electroactive biofilms. ${ }^{149,150}$ In the neighbouring scientific area of microbial corrosion, AFM has been successfully used to approach biofilmelectrode interactions. These studies should be a fruitful source of inspiration in the field of microbial anodes. ${ }^{151}$

In the domain of local control of spatial heterogeneities, the construction of artificial electroactive biofilms, with wellcontrolled configurations and compositions at the micrometre level, is also becoming an exciting way to deal with the complexity of natural EA biofilms. Protein bioelectrochemistry has already produced sophisticated interfaces with successive, organised layers, including different enzymes, redox mediators, ions, etc. ${ }^{152}$ and similar interesting attempts have started to be made in the field of microbial electroactive biofilms. ${ }^{153-155}$

Coupling UV/visible or Raman spectroscopy with electroanalysis has already made several valuable contributions. ${ }^{130}$ The specific electrode materials required for these techniques may affect the ET pathways in some cases (see Section 6.2). This must be kept in mind but it does not detract from the great interest of these techniques. Furthermore, the recent creation of G. sulfurreducens strains that produce a short-lived fluorescent protein should provide leverage to the power of the method. ${ }^{156}$ The engineered strains express the gene of the fluorescent protein under the control of the promoter of a gene of interest, and it thus becomes possible to examine, directly and in real-time, the spatial distribution of a specific gene expression related to ET.

Microscopic imaging has generally been performed at the end of the experiments, after the bioanode has been extracted from the electrochemical set-up and the appropriate treatment applied. Ex situ imaging techniques are not specific to electroanalytical conditions and were consequently not reviewed in this article. On this topic, recent comprehensive review by Harnisch and Rabaey is well worth consulting. ${ }^{157}$ Ex situ imaging at the end of the experiments must not be neglected, but coupling real-time microscopy with electroanalytical set-ups is obviously of essential interest. Sophisticated techniques, like microtoming coupled with microarray analysis, can go further towards the spatial imaging of the metabolic status of the cells. ${ }^{158}$ The extremely wide range of possibilities is impressive when we consider the possible combinations of confocal laser scanning microscopy with fluorescent dyes. Many such couplings have been successfully applied in biofilm studies, regardless of any electrochemical considerations. An excellent review has recently listed the different parts of biofilms (exopolymeric substances, enzyme activities, extracellular redox activities, extracellular DNA, etc.) that can be detected in situ in a biofilm matrix. ${ }^{159}$

The few items developed above illustrate an essential direction for future work. The most impressive fundamental advances have been achieved by coupling different analytical techniques in the strong framework of carefully designed electroanalysis set-ups. Coupling different techniques is undoubtedly the most efficient avenue towards in-depth progress. The association of methods coming from the three different fields of physical chemistry, microbiology (particularly the molecular biology tools) and theoretical modelling should be the most encouraging way to advance in electroanalysis. Among the multitude of possible associations that are offered, the researchers' intuition in choosing the most relevant combinations should open up exciting new avenues to decipher the fundamental processes and boost technological performance.

\subsection{From fundamental advances towards "real world" progress}

"Potentiostatic bioanode experiments bear the danger of over interpreting bioanode functions in realistic systems, where all the named insufficiencies (see Section 2.1) and reaction limitations directly influence the bioanode function." We took the liberty of reusing this relevant sentence from a reviewer of the present paper, as it expresses an apparently rather common feeling in the BES research community. Actually, there is no reason to consider electroanalytical conditions and the realistic "real world" systems (i.e. MFC, MEC and other BES production equipment) as being in opposition to one another. They both help to enhance the practical development of BES to industrial applications when implemented in a proper engineering strategy.

In a conventional engineering approach, each component of a complex system must firstly be characterized individually in well controlled conditions. Designing a car, a chemical unit, an artificial heart or any technological device requires the intrinsic behaviour of each component to be accurately characterized first. For BES, this is the function of electroanalysis. The fundamental information acquired on each component (anode, cathode, separator if any, electrolyte(s), etc.) must then be used to feed a theoretical model of the whole system in order to design the optimal configuration of the BES prototype. Then, comparison of the theoretical data with the experimental performance obtained with the prototype will lead to the identification and the quantification of the insufficiencies present in the prototype (oxygen diffusion from the cathode of an MFC, hydrogen diffusion from the cathode of an MEC, increased internal resistance due to (bio-)fouling, etc.). These limitation sources can also be reproduced and investigated experimentally in controlled 3-electrode set-ups to accurately assess their impact. The theoretical model and the prototype must be improved in parallel through successive generations until the best possible pilot has been designed with regard to the state of the art. We hope the present paper shows that a large basis of efficient electroanalytical approaches now exists so that engineering-based strategies ${ }^{15}$ can start to be implemented for BES development. 


\section{Acknowledgements}

This work was part of the "Biorare" project (ANR-10-BTBR-02), partly funded by the French Agence Nationale de la Recherche (ANR) and the Comité des Investissements d'Avenir.

\section{Notes and references}

1 B. H. Kim, H. J. Kim, M. S. Hyun and D. H. Park, J. Microbiol. Biotechnol., 1999, 9, 127-131.

2 B. H. Kim, T. Ikeda, H. S. Park, H. J. Kim, M. S. Hyun, K. Kano, K. Takagi and H. Tatsumi, Biotechnol. Tech., 1999, 13, 475-478.

3 D. R. Bond, D. E. Holmes, L. M. Tender and D. R. Lovley, Science, 2002, 295, 483-485.

4 L. M. Tender, C. E. Reimers, H. A. Stecher, D. E. Holmes, D. R. Bond, D. A. Lowy, K. Pilobello, S. J. Fertig and D. R. Lovley, Nat. Biotechnol., 2002, 20, 821-825.

5 D. Pant, A. Singh, G. Van Bogaert, S. I. Olsen, P. S. Nigam, L. Diels and K. Vanbroekhoven, RSC Adv., 2012, 2, 1248-1263.

6 A. P. Borole, G. Reguera, B. Ringeisen, Z.-W. Wang, Y. Feng and B. H. Kim, Energy Environ. Sci., 2011, 4, 4813-4834.

7 T. H. J. A. Sleutels, A. Ter Heijne, C. J. N. Buisman and H. V. M. Hamelers, ChemSusChem, 2012, 5, 1012-1019.

8 K. Rabaey, P. Girguis and L. K. Nielsen, Curr. Opin. Biotechnol., 2011, 22, 371-377.

9 D. R. Lovley and K. P. Nevin, Curr. Opin. Biotechnol., 2011, 22, 441-448.

10 J. Dolfing, ISME J., 2014, 8, 4-5.

11 S. Chen, G. He, Q. Liu, F. Harnisch, Y. Zhou, Y. Chen, M. Hanif, S. Wang, X. Peng, H. Hou and U. Schröder, Energy Environ. Sci., 2012, 5, 9769-9772.

12 E. S. Friedman, M. A. Rosenbaum, A. W. Lee, D. A. Lipson, B. R. Land and L. T. Angenent, Biosens. Bioelectron., 2012, 32, 309-313.

13 C. I. Torres, A. K. Marcus, P. Parameswaran and B. E. Rittman, Environ. Sci. Technol., 2008, 42, 6593-6597.

14 R. Rousseau, X. Dominguez-Benetton, M.-L. Delia and A. Bergel, Electrochem. Commun., 2013, 33, 1-4.

15 D. Pocaznoi, B. Erable, L. Etcheverry, M.-L. Delia and A. Bergel, Phys. Chem. Chem. Phys., 2012, 14, 13332-13343.

16 H. V. M. Hamelers, A. Ter Heijne, N. Stein, R. A. Rozendal and C. J. N. Buisman, Bioresour. Technol., 2011, 102, 381-387.

17 S. F. Ketep, E. Fourest and A. Bergel, Bioresour. Technol., 2013, 149, 117-125.

18 J. P. Busalmen and S. R. de Sanchez, Appl. Environ. Microbiol., 2005, 71, 6235-6240.

19 P. Sebastian Bonanni, D. F. Bradley, G. D. Schrott and J. Pablo Busalmen, ChemSusChem, 2013, 6, 711-720.

20 A. Kumar, A. Siggins, K. Katuri, T. Mahony, V. O'Flaherty, P. Lens and D. Leech, Chem. Eng. J., 2013, 230, 532-536.

21 D. R. Bond and D. R. Lovley, Appl. Environ. Microbiol., 2003, 69, 1548-1555.
22 P. Parameswaran, C. I. Torres, H.-S. Lee, B. E. Rittmann and R. Krajmalnik-Brown, Bioresour. Technol., 2011, 102, 263-271.

23 J. F. Miceli, P. Parameswaran, D.-W. Kang, R. KrajmalnikBrown and C. I. Torres, Environ. Sci. Technol., 2012, 46, 10349-10355.

24 P. Parameswaran, T. Bry, S. C. Popat, B. G. Lusk, B. E. Rittmann and C. I. Torres, Environ. Sci. Technol., 2013, 47, 4934-4940.

25 E. Marsili, J. Sun and D. R. Bond, Electroanalysis, 2010, 22, 865-874.

26 S. Srikanth, E. Marsili, M. C. Flickinger and D. R. Bond, Biotechnol. Bioeng., 2008, 99, 1065-1073.

27 C. I. Torres, A. K. Marcus and B. E. Rittmann, Biotechnol. Bioeng., 2008, 100, 872-881.

28 B. Cercado-Quezada, M.-L. Délia and A. Bergel, Electrochem. Commun., 2011, 13, 440-443.

29 B. Cercado-Quezada, M.-L. Delia and A. Bergel, J. Appl. Electrochem., 2010, 40, 225-232.

30 Y. Liu, F. Harnisch, K. Fricke, U. Schröder, V. Climent and J. M. Feliu, Biosens. Bioelectron., 2010, 25, 2167-2171.

31 X. Wang, Y. Feng, N. Ren, H. Wang, H. Lee, N. Li and Q. Zhao, Electrochim. Acta, 2009, 54, 1109-1114.

32 D. A. Finkelstein, L. M. Tender and J. G. Zeikus, Environ. Sci. Technol., 2006, 40, 6990-6995.

33 B. Erable, M.-A. Roncato, W. Achouak and A. Bergel, Environ. Sci. Technol., 2009, 43, 3194-3199.

34 P. Salvin, C. Roos and F. Robert, Bioresour. Technol., 2012, 120, 45-51.

35 S. Parot, M.-L. Délia and A. Bergel, Electrochim. Acta, 2008, 53, 2737-2742.

36 S. Parot, M.-L. Delia and A. Bergel, Bioresour. Technol., 2008, 99, 4809-4816.

37 S. Dulon, S. Parot, M.-L. Délia and A. Bergel, J. Appl. Electrochem., 2007, 37, 173-179.

38 E. S. Friedman, K. E. Miller, D. A. Lipson and L. T. Angenent, Minerals, 2013, 3, 318-336.

39 B. Cercado, N. Byrne, M. Bertrand, D. Pocaznoi, M. Rimboud, W. Achouak and A. Bergel, Bioresour. Technol., 2013, 134, 276-284.

40 S. F. Ketep, A. Bergel, M. Bertrand, W. Achouak and E. Fourest, Bioresour. Technol., 2013, 127, 448-455.

41 S. F. Ketep, A. Bergel, M. Bertrand, W. Achouak and E. Fourest, Biochem. Eng. J., 2013, 73, 12-16.

42 X. Zhu, M. D. Yates and B. E. Logan, Electrochem. Commun., 2012, 22, 116-119.

43 G. D. Schrott, P. S. Bonanni, L. Robuschi, A. Esteve-Nuñez and J. P. Bulsamen, Electrochim. Acta, 2011, 56, 10791-10795.

44 S. M. Strycharz, R. H. Glaven, M. V. Coppi, S. M. Gannon, L. A. Perpetua, A. Liu, K. P. Nevin and D. R. Lovley, Bioelectrochemistry, 2011, 80, 142-150.

45 K. P. Katuri, P. Kavanagh, S. Rengaraj and D. Leech, Chem. Commun., 2010, 46, 4758-4760.

46 Y. Liu, H. Kim, R. Franklin and D. R. Bond, Energy Environ. Sci., 2010, 3, 1782-1788.

47 J. Wei, P. Liang, X. Cao and X. Huang, Environ. Sci. Technol., 2010, 44, 3187-3191. 
48 H. Yi, K. P. Nevin, B.-C. Kim, A. E. Franks, A. Klimes, L. M. Tender and D. R. Lovley, Biosens. Bioelectron., 2009, 24, 3498-3503.

49 J. P. Bulsamen, A. Esteve-nuñez and J. M. Feliu, Environ. Sci. Technol., 2008, 42, 2445-2450.

50 C. Dumas, R. Basseguy and A. Bergel, Electrochim. Acta, 2008, 53, 3200-3209.

51 C. Dumas, R. Basseguy and A. Bergel, Electrochim. Acta, 2008, 53, 5235-5241.

52 H. Richter, K. McCarthy, K. P. Nevin, J. P. Johnson, V. M. Rotello and D. R. Lovley, Langmuir, 2008, 24, 4376-4379.

53 G. Reguera, K. P. Nevin, J. S. Nicoll, S. F. Covalla, T. L. Woodard and D. R. Lovley, Appl. Environ. Microbiol., 2006, 72, 7345-7348.

54 L. Soussan, B. Erable, M.-L. Delia and A. Bergel, Electrochem. Commun., 2013, 33, 35-38.

55 J. P. Busalmen, A. Esteve-Nunez, A. Berna and J. M. Feliu, Angew. Chem., Int. Ed., 2008, 47, 4874-4877.

56 B. Virdis, F. Harnisch, D. J. Batstone, K. Rabaey and B. C. Donose, Energy Environ. Sci., 2012, 5, 7017-7024.

57 J. Pablo Busalmen, A. Esteve-Nunez, A. Berna and J. Miguel Feliu, Bioelectrochemistry, 2010, 78, 25-29.

58 A. A. Carmona-Martinez, F. Harnisch, L. A. Fitzgerald, J. C. Biffinger, B. R. Ringeisen and U. Schröder, Bioelectrochemistry, 2011, 81, 74-80.

59 J. M. Flynn, D. E. Ross, K. A. Hunt, D. R. Bond and J. A. Gralnick, mBio, 2010, 1, e00190.

60 E. J. Cho and A. D. Ellington, Bioelectrochemistry, 2007, 70, 165-172.

61 M. Rosenbaum, H. Y. Bar, Q. K. Beg, D. Segrè, J. Booth, M. A. Cotta and L. T. Angenent, PLoS One, 2012, 7, e30827.

62 E. Marsili, D. B. Baron, I. D. Shikhare, D. Coursolle, J. A. Gralnick and D. R. Bond, Proc. Natl. Acad. Sci. U. S. A., 2008, 105, 3968-3973.

63 L. Peng, S.-J. You and J.-Y. Wang, Biosens. Bioelectron., 2010, 25, 2530-2533.

64 H. Liu, S. Matsuda, T. Kawai, K. Hashimoto and S. Nakanishi, Chem. Commun., 2011, 47, 3870-3872.

65 N. Tajima, A. Kouzuma, K. Hashimoto and K. Watanabe, Biosci., Biotechnol., Biochem., 2011, 75, 2229-2233.

66 A. A. Carmona-Martinez, F. Harnisch, U. Kuhlicke, T. R. Neu and U. Schroeder, Bioelectrochemistry, 2013, 93, 23-29.

67 C. Feng, X. Yue, F. Li and C. Wei, Biosens. Bioelectron., 2013, 39, 51-56.

68 A. Jain, X. Zhang, G. Pastorella, J. O. Connolly, N. Barry, R. Woolley, S. Krishnamurthy and E. Marsili, Bioelectrochemistry, 2012, 87, 28-32.

69 A. Jain, J. O. Connolly, R. Woolley, S. Krishnamurthy and E. Marsili, Int. J. Electrochem. Sci., 2013, 8, 1778-1793.

70 H. Liu, S. Matsuda, S. Kato, K. Hashimoto and S. Nakanishi, ChemSusChem, 2010, 3, 1253-1256.

71 X. Zhang, M. Epifanio and E. Marsili, Electrochim. Acta, 2013, 102, 252-258.

72 A. Venkataraman, M. Rosenbaum, J. B. A. Arends, R. Halitschke and L. T. Angenent, Electrochem. Commun., 2010, 12, 459-462.
73 Y.-F. Wang, M. Masuda, S. Tsujimura and K. Kano, Biotechnol. Bioeng., 2008, 101, 579-586.

74 S. K. Chaudhuri and D. R. Lovley, Nat. Biotechnol., 2003, 21, 1229-1232.

75 M. Malki, L. De lacey Antonio, N. Rodrfguez, R. Amils and V. M. Fernandez, Appl. Environ. Microbiol., 2008, 74, 4472-4476.

76 D. R. Bond and D. R. Lovley, Appl. Environ. Microbiol., 2005, 71, 2186-2189.

77 O. Nercessian, S. Parot, M.-L. Delia, A. Bergel and W. Achouak, PLoS One, 2012, 7, e34216.

78 J. P. Badalamenti, R. Krajmalnik-Brown and C. I. Torres, mBio, 2013, 4, e00144.

79 S. Freguia, M. Masuda, S. Tsujimura and K. Kano, Bioelectrochemistry, 2009, 76, 14-18.

80 K. Hasan, S. A. Patil, K. Gorecki, D. Leech, C. Hagerhall and L. Gorton, Bioelectrochemistry, 2013, 93, 30-36.

81 N. S. Malvankar, M. T. Tuominen and D. R. Lovley, Energy Environ. Sci., 2012, 5, 8651-8659.

82 M. Vargas, N. S. Malvankar, P.-L. Tremblay, C. Leang, J. A. Smith, P. Patel, O. Synoeyenbos-West, K. P. Nevin and D. R. Lovley, mBio, 2013, 4, e00105.

83 C. Leang, N. S. Malvankar, A. E. Franks, K. P. Nevin and D. R. Lovley, Energy Environ. Sci., 2013, 6, 1901-1908.

84 J.-Y. Nam, J. C. Tokash and B. E. Logan, Int. J. Hydrogen Energy, 2011, 36, 10550-10556.

85 C. I. Torres, R. Krajmalnik-Brown, P. Parameswaran, A. K. Marcus, G. Wanger, Y. A. Gorby and B. E. Rittman, Environ. Sci. Technol., 2009, 43, 9519-9524.

86 B. Erable, L. Etcheverry and A. Bergel, Biofouling, 2011, 27, 319-326.

87 S. Chen, H. Hou, F. Harnisch, S. A. Patil, A. A. CarmonaMartinez, S. Agarwal, Y. Zhang, S. Sinha-Ray, A. L. Yarin, A. Greiner and U. Schröder, Energy Environ. Sci., 2011, 4, 1417-1421.

88 S. Chen, G. He, A. A. Carmona-Martinez, S. Agarwal, A. Greiner, H. Hou and U. Schroeder, Electrochem. Commun., 2011, 13, 1026-1029.

89 G. He, Y. Gu, S. He, U. Schröder, S. Chen and H. Hou, Bioresour. Technol., 2011, 102, 10763-10766.

90 S. A. Patil, F. Harnisch, C. Koch, T. Hübschmann, I. Fetzer, A. A. Carmona-Martinez, S. Müller and U. Schröder, Bioresour. Technol., 2011, 102, 9683-9690.

91 Y. Liu, F. Harnisch, K. Fricke, R. Sietmann and U. Schröder, Biosens. Bioelectron., 2008, 24, 1006-1011.

92 P. M. Shrestha, K. P. Nevin, M. Shrestha and D. R. Lovley, mBio, 2013, 4, e00591.

93 H. R. Luckarift, S. R. Sizemore, K. E. Farrington, J. Roy, C. Lau, P. B. Atanassov and G. R. Johnson, ACS Appl. Mater. Interfaces, 2012, 4, 2082-2087.

94 R. C. Wagner, D. I. Call and B. E. Logan, Environ. Sci. Technol., 2010, 44, 6036-6041.

95 X. Zhu, J. C. Tokash, Y. Hong and B. E. Logan, Bioelectrochemistry, 2013, 90, 30-35.

96 P. Aelterman, S. Freguia, J. Keller, W. Verstraete and K. Rabaey, Appl. Microbiol. Biotechnol., 2008, 78, 409-418. 
97 X. Wang, Y. Feng, J. Liu, H. Lee and N. Ren, J. Chem. Technol. Biotechnol., 2010, 86, 590-594.

98 R. Kannaiah Goud and S. Venkata Mohan, Bioresour. Technol., 2013, 137, 160-170.

99 K. Fricke, F. Harnisch and U. Schröder, Energy Environ. Sci., 2008, 1, 144-147.

100 B. Cercado, L. Felipe Chazaro-Ruiz, V. Ruiz, I. de Jesus Lopez-Prieto, G. Buitron and E. Razo-Flores, Biosens. Bioelectron., 2013, 50, 373-381.

101 X. Zhu, M. D. Yates, M. C. Hatzell, H. A. Rao, P. E. Saikaly and B. E. Logan, Environ. Sci. Technol., 2014, 48, 1352-1358.

102 A. S. Commault, G. Lear, M. A. Packer and R. J. Weld, Bioresour. Technol., 2013, 139, 226-234.

103 J. Bader, E. Mast-Gerlach, M. K. Popovic, R. Bajpai and U. Stahl, J. Appl. Microbiol., 2010, 109, 371-387.

104 T. H. Pham, N. Boon, P. Aelterman, P. Clauwaert, L. De Schamphelaire, L. Vanhaecke, K. De Maeyer, M. Hoefte, W. Verstraete and K. Rabaey, Appl. Microbiol. Biotechnol., 2008, 77, 1119-1129.

105 M. A. Rosenbaum, H. Y. Bar, Q. K. Beg, D. Segre, J. Booth, M. A. Cotta and L. T. Angenent, Bioresour. Technol., 2011, 102, 2623-2628.

106 H. Richter, M. Lanthier, K. P. Nevin and D. R. Lovley, Appl. Environ. Microbiol., 2007, 73, 5347-5353.

107 A. Venkataraman, M. A. Rosenbaum, S. D. Perkins, J. J. Werner and L. T. Angenent, Energy Environ. Sci., 2011, 4, 4550-4559.

108 D. Pocaznoi, B. Erable, L. Etcheverry, M.-L. Delia and A. Bergel, Bioresour. Technol., 2012, 114, 334-341.

109 B. Erable and A. Bergel, Bioresour. Technol., 2009, 100, 3302-3307.

110 K. P. Nevin, B.-C. Kim, R. H. Glaven, J. P. Johnson, T. L. Woodard, B. A. Methe, R. J. DiDonato, S. F. Covalla, A. E. Franks, A. Liu and D. R. Lovley, PLoS One, 2009, 4, e5628.

111 S. M. Strycharz-Glaven and L. M. Tender, ChemSusChem, 2012, 5, 1106-1118.

112 P. Sebastian Bonanni, G. D. Schrott, L. Robuschi and J. P. Busalmen, Energy Environ. Sci., 2012, 5, 6188-6195.

113 A. Okamoto, K. Hashimoto and R. Nakamura, Bioelectrochemistry, 2012, 85, 61-65.

114 D. Pocaznoi, A. Calmet, L. Etcheverry, B. Erable and A. Bergel, Energy Environ. Sci., 2012, 5, 9645-9652.

115 H. Richter, K. P. Nevin, H. Jia, D. A. Lowy, D. R. Lovley and L. M. Tender, Energy Environ. Sci., 2009, 2, 506-516.

116 S. M. Strycharz, A. P. Malanoski, R. M. Snider, H. Yi, D. R. Lovley and L. M. Tender, Energy Environ. Sci., 2011, 4, 896-913.

117 D. Pocaznoi, B. Erable, M.-L. Délia and A. Bergel, Energy Environ. Sci., 2012, 5, 5287-5296.

118 R. Rousseau, M.-L. Delia and A. Bergel, Energy Environ. Sci., 2014, 7, 1079-1094.

119 N. S. Malvankar, M. Vargas, K. P. Nevin, A. E. Franks, C. Leang, B.-C. Kim, K. Inoue, T. Mester, S. F. Covalla, J. P. Johnson, V. M. Rotello, M. T. Tuominen and D. R. Lovley, Nat. Nanotechnol., 2011, 6, 573-579.
120 S. M. Strycharz-Glaven, R. M. Snider, A. Guiseppi-Elie and L. M. Tender, Energy Environ. Sci., 2011, 4, 4366-4379.

121 N. S. Malvankar, M. T. Tuominen and D. R. Lovley, Energy Environ. Sci., 2012, 5, 6247-6249.

122 S. M. Strycharz-Glaven and L. M. Tender, Energy Environ. Sci., 2012, 5, 6250-6255.

123 X. Dominguez-Benetton, S. Sevda, K. Vanbroekhoven and D. Pant, Chem. Soc. Rev., 2012, 41, 7228-7246.

124 F. Melin and P. Hellwig, Biol. Chem., 2013, 394, 593-609.

125 P. A. Ash and K. A. Vincent, Chem. Commun., 2012, 48, 1400-1409.

126 D. Millo, Biochem. Soc. Trans., 2012, 40, 1284-1290.

127 Y. Liu, H. Kim, R. R. Franklin and D. R. Bond, ChemPhysChem, 2011, 12, 2235-2241.

128 A. Jain, G. Gazzola, A. Panzera, M. Zanoni and E. Marsii, Electrochim. Acta, 2011, 56, 10776-10785.

129 A. Kuzume, U. Zhumaev, J. Li, Y. Fu, M. Fueeg, A. EsteveNunez and T. Wandlowski, Electrochim. Acta, 2013, 112, 933-942.

130 H. K. Ly, F. Harnisch, S.-F. Hong, U. Schroeder, P. Hildebrandt and D. Millo, ChemSusChem, 2013, 6, 487-492.

$131 \mathrm{~W}$. Wu, L. Bai, X. Liu, Z. Tang and Z. Gu, Electrochem. Commun., 2011, 13, 872-874.

132 A. A. Carmona-Martinez, M. Pierra, E. Trably and N. Bernet, Phys. Chem. Chem. Phys., 2013, 15, 19699-19707.

133 S. Patil, F. Harnisch and U. Schroeder, ChemPhysChem, 2010, 11, 2834-2837.

134 B. Erable, N. Duteanu, S. M. S. Kumar, Y. Feng, M. M. Ghangrekar and K. Scott, Electrochem. Commun., 2009, 11, 1547-1549.

135 S. Chen, Q. Liu, G. He, Y. Zhou, M. Hanif, X. Peng, S. Wang and H. Hou, J. Mater. Chem., 2012, 22, 18609-18613.

136 S. Chen, G. He, X. Hu, M. Xie, S. Wang, D. Zeng, H. Hou and U. Schröder, ChemSusChem, 2012, 5, 1059-1063.

137 R. M. Snider, S. M. Strycharz-Glaven, S. D. Tsoi, J. S. Erickson and L. M. Tender, Proc. Natl. Acad. Sci. U. S. A., 2012, 109, 15467-15472.

138 A. L. Kane, D. R. Bond and J. A. Gralnick, Synth. Biol., 2013, 2, 93-101.

139 A. Rinaldi, B. Mecheri, V. Garavaglia, S. Licoccia, P. Di Nardo and E. Traversa, Energy Environ. Sci., 2008, 1, 417-429.

140 Y. Qiao, S.-J. Bao and C. M. Li, Energy Environ. Sci., 2010, 3, 544-553.

141 M. Zhou, M. Chi, J. Luo, H. He and T. Jin, J. Power Sources, 2011, 196, 4427-4435.

142 Wu et al., 2011.

143 A. El Kasmi, M. C. Leopold, R. Galligan, R. T. Robertson, S. S. Saavedra, K. El Kacemi and E. F. Bowden, Electrochem. Commun., 2002, 4, 177-181.

144 S. R. Crittenden, C. J. Sund and J. J. Sumner, Langmuir, 2006, 22, 9473-9476.

145 M. M. C. dos Santos, P. M. P. de Sousa, M. L. S. Goncalves, H. Lopes, I. Moura and J. J. G. Moura, J. Electroanal. Chem., 1999, 464, 76-84.

146 A. Bergel and M. Comtat, J. Electroanal. Chem., 1991, 302, 219-231. 
147 A. J. Bard and L. R. Faulkner, Electrochemical Methods: Fundamentals and Applications, Wiley Interscience, 2nd edn, 2001.

148 S. F. Ketep, A. Bergel, A. Calmet and B. Erable, Energy Environ. Sci., 2014, 7, 1633-1637.

149 G. Reguera, K. D. McCarthy, T. Mehta, J. S. Nicoll, M. T. Tuominen and D. R. Lovley, Nature, 2005, 435, 1098-1101.

150 Y. A. Gorby, S. Yanina, J. S. McLean, K. M. Rosso, D. Moyles, A. Dohnalkova, T. J. Beveridge, I. S. Chang, B. H. Kim, K. S. Kim, D. E. Culley, S. B. Reed, M. F. Romine, D. A. Saffarini, E. A. Hill, L. Shi, D. A. Elias, D. W. Kennedy, G. Pinchuk, K. Watanabe, S. Ishii, B. Logan, K. H. Nealson and J. K. Fredrickson, Proc. Natl. Acad. Sci. U. S. A., 2006, 103, 11358-11363.

151 I. B. Beech, J. R. Smith, A. A. Steele, I. Penegar and S. A. Campbell, Colloids Surf., B, 2002, 23, 231-247.
152 S. Ben-Ali, D. A. Cook, P. N. Bartlett and A. Kuhn, J. Electroanal. Chem., 2005, 579, 181-187.

153 H. R. Luckarift, S. R. Sizemore, J. Roy, C. Lau, G. Gupta, P. Atanassov and G. R. Johnson, Chem. Commun., 2010, 46, 6048-6050.

154 Y.-Y. Yu, H. Chen, Y.-C. Yong, D.-H. Kim and H. Song, Chem. Commun., 2011, 47, 12825-12827.

155 J. N. Roy, H. R. Luckarift, S. R. Sizemore, K. E. Farrington, C. Lau, G. R. Johnson and P. Atanassov, Enzyme Microb. Technol., 2013, 53, 123-127.

156 A. E. Franks, R. H. Glaven and D. R. Lovley, ChemSusChem, 2012, 5, 1092-1098.

157 F. Harnisch and K. Rabaey, ChemSusChem, 2012, 5, 1027-1038.

158 A. E. Franks, K. P. Nevin, R. H. Glaven and D. R. Lovley, ISME J., 2010, 4, 509-519.

159 H.-C. Flemming and J. Wingender, Nat. Rev. Microbiol., 2010, 8, 623-633. 